\title{
Operational thresholds of moored ships at the oil terminal of inner port of A Coruña (Spain)
}

\author{
Andres Figuero ${ }^{\mathrm{a}}$, José Sande ${ }^{\mathrm{a}}$, Enrique Peña ${ }^{\mathrm{a}}$, Alberto Alvarellos ${ }^{\mathrm{b}}$, Juan R. \\ Rabuñal $^{c}$, Enrique Maciñeira ${ }^{\mathrm{d}}$ \\ ${ }^{a}$ Water and Environmental Engineering Group (GEAMA), Universidade da Coruña, Campus Elviña S/n, \\ 15071, A Coruña, Spain \\ ${ }^{b}$ Centre for Research of Information and Communication Technologies (CITIC), Universidade da Coruña, \\ Campus Elviña S/n, 15071, A Coruña, Spain \\ ${ }^{c}$ Department of Computer Science, Universidade da Coruña, Campus Elviña S/n, 15071, A Coruña, Spain \\ ${ }^{d}$ Port Authority of A Coruña, Avenida de La Marina 3, 15001, A Coruña, Spain
}

\begin{abstract}
Minimizing the stay of a vessel in port can lead to improvements in harbor efficiency. Currently, downtimes of cargo operations or their performance reduction because of excessive vessel motion are especially relevant. This work aims to evaluate the operational conditions of moored vessels in the inner port of A Coruña (Spain), comparing them with motion thresholds established by international standards for cargo operations. To this end, motions of 19 ships were monitored. Data analysis revealed large angular motions, particularly roll and yaw, including amplitudes that exceeded the limiting criteria of the standards in most of the analyzed vessels, with no registered downtime. Regarding linear movements, heave and surge recorded lower amplitudes compared to the values of standard thresholds. The specific behavior of each vessel was analyzed in terms of its size, maritime conditions, and mooring location. Field campaigns such as those performed in this work are an effective way of analyzing the operational conditions of ports, which could help in identifying problems in the mooring zone.
\end{abstract}

\section{Keywords}

Operational conditions; Port downtimes; Moored ships; Ship motions; Maritime conditions; Field campaigns 


\section{Introduction}

Improving the port efficiency involves reducing costs related to cargo handling operations. These are affected by the dynamic behavior of moored vessels. When a ship experiences large movements, negative consequences can occur. These include decrease in operation efficiency, breaking of mooring lines, or even damages to the vessel and port facilities. Excessive motions are usually caused by wave action and related phenomena, such as long waves or harbor resonance (González-Marco et al., 2008; Kwak and Pyun, 2013; Sakakibara et al., 2001).

A widely used tool to characterize the dynamic behavior of moored vessels is the small-scale physical model, which can reproduce in simplified form the characteristics of ships, mooring arrangement, and the wave, wind, and currents loads. However, to make this instrument reliable, an intensive calibration process and accurate model construction are required. Different methodologies and modeling technologies are described by Cornett (2014). Physical models have been used to analyze, among others, the effects of mooring tension and fender stiffness on the response of moored vessels (Rosa-Santos et al., 2014; Taveira Pinto et al., 2008) and to optimize the design of berthing zones in port facilities (Baker et al., 2016; Davies et al., 2001).

Recently, numerical modeling studies have gained much research attention. Numerical models can reproduce the behavior of moored ships and evaluate their movements and mooring loads with an acceptable computational cost. Several researchers have used this approach for their research (Bont et al., 2010; van der Molen et al., 2015). Moreover, the combination of numerical and physical models has also been used, such as in the study by Taveira Pinto et al. (2008), to integrate the advantages of both methods. However, these tools, especially physical models, have the disadvantage of not reproducing the variations that ships experience in the position of their centers of gravity during the cargo operation, or changes in the initial pretension of mooring lines, which can explain certain dynamic patterns.

The evaluation of the real response of a moored vessel is a less explored field. The authors could only find few examples in the literature in which a real ship was monitored during its stay in port (Jensen et al., 1991; López and Iglesias, 2014). Most of the existing data come from observations of port operators and, as mentioned previously, from physical and numerical simulations.

For years now, several institutions have recognized the need for updating the operational limits established by national and international standards (PIANC, 1995; Puertos del Estado, 2011) in order to adapt them to the new requirements of modern ports and their cargo handling equipment. In this context, the aim of the present study is to evaluate if the movement thresholds proposed by PIANC (1995) and the Spanish standard ROM 2.0-11 (Puertos del Estado, 2011) for loading and unloading operations, are applicable to the facilities of the inner port of A Coruña (Spain). The monitoring of different types of vessels during their stay in port is proposed as an essential tool to achieve this goal.

\section{Case study: inner port of A Coruña}

The inner port of A Coruña is located inside the city of A Coruña, in the northwest part of Spain (Fig. 1). The port has a strategic geographical situation, being located in the main international maritime routes between the north of Europe, the Mediterranean and Africa, and between Western Europe and America. It is a multipurpose complex that constitutes the first industry of the city. The facilities comprise an oil terminal with four jetties, different docks for loading/unloading of dry bulks and general cargoes, a container terminal with a capacity of 2330 TEUs and mooring zones for cruise ships and leisure vessels (Fig. 1). The entrance to the port is protected by a $1330 \mathrm{~m}$ long rubble-mound breakwater, so-called the Barrie de la Maza Breakwater. 


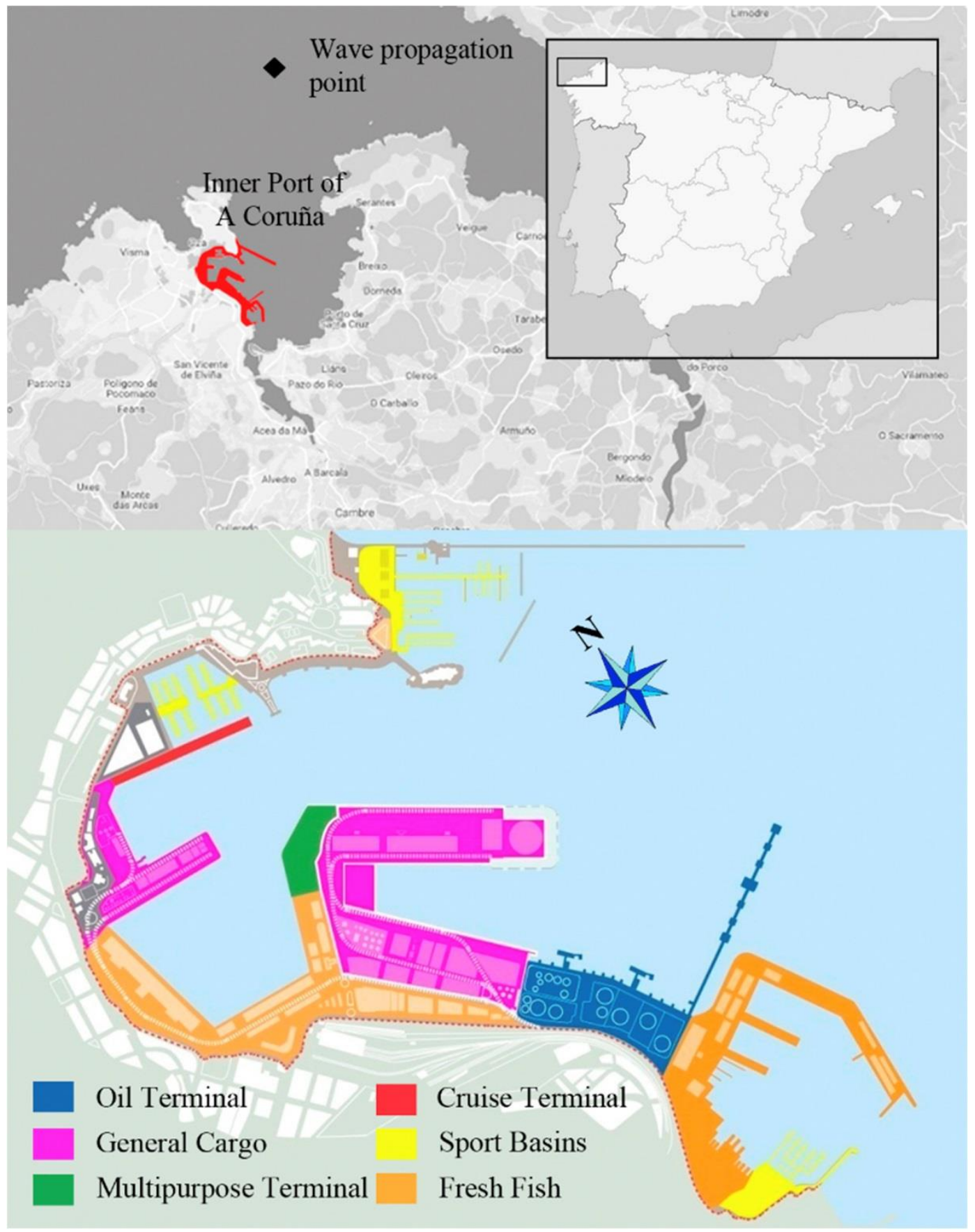

Fig. 1. Location and general layout of the inner port of A Coruña (Spain). The wave propagation point used in this study is highlighted in the upper part. 
This study focuses on the evaluation of vessel movements that operate in the 1st, 2nd, and 3rd jetty of the oil terminal, and in the San Diego dock, which is used for the loading and unloading of general cargo ships (Fig. 2).

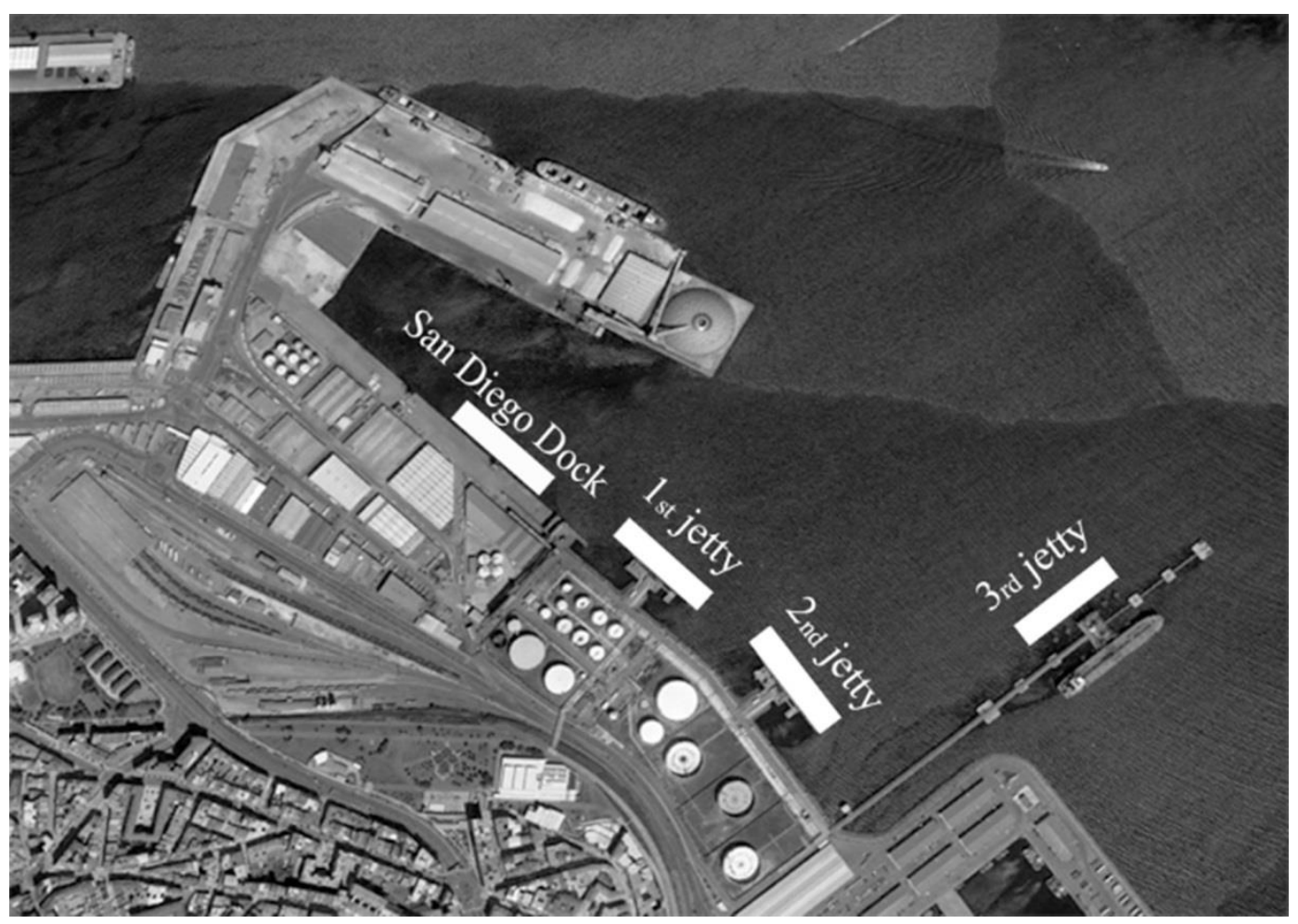

Fig. 2. Analyzed mooring locations (white rectangles).

\section{Methodology}

\subsection{Study fleet}

During the field campaign carried out between spring 2015 and autumn 2015 to winter 2016, 19 vessels of four different types were monitored (six gas tankers, four oil tankers, seven chemical tankers, and two general cargo ships), with a mean stay in port from 0.5 to 1.5 days (Table 1 ). In this period, vessels were instrumented to analyze their motions during the cargo operation. Some of the ships were studied several times during the field campaign, in different loading and unloading cycles, e.g., Sichem Singapore chemical tanker (named as I and II) or Scali del Teatro gas tanker (named as I, II, and III); both were monitored twice and three times, respectively. The ships' position within the port and the usual mooring arrangement of each berthing zone are shown in Fig. 3. As can be observed, vessels moored at the 1st and 2 nd jetties have an auxiliary stern line tended to a small mooring buoy. Its main function is to facilitate the unmooring maneuver of the vessel in emergency situations, and does not contribute to the ship stability during the cargo operation. 
Table 1. Study fleet (sorted by type and descending amplitudes of roll motion), deadweight tonnage (DWT), overall length, mooring location, and mooring configuration (bow lines - bow breast lines - bow springs - stern springs - stern breast lines - stern lines) of each analyzed ship.

\begin{tabular}{|c|c|c|c|c|c|}
\hline Ship name & Type & DWT $(t)$ & Length (m) & Mooring location & Mooring config \\
\hline Scali del Teatro - III & Gas tanker & 3600 & 88.4 & $1^{\text {st }}$ jetty & $3-0-3-3-0-3$ \\
\hline Scali Reali & Gas tanker & 3600 & 88.4 & $2^{\text {nd }}$ jetty & $3-0-3-3-0-3$ \\
\hline Scali del Teatro - I & Gas tanker & 3600 & 88.4 & $2^{\text {nd }}$ jetty & $3-0-3-3-0-3$ \\
\hline Maingas & Gas tanker & 3932 & 96.6 & $2^{\text {nd }}$ jetty & $3-0-2-2-0-3$ \\
\hline Matthew & Gas tanker & 3600 & 88.4 & $2^{\text {nd }}$ jetty & $3-0-3-3-0-3$ \\
\hline Scali del Teatro - II & Gas tanker & 3600 & 88.4 & $2^{\text {nd }}$ jetty & $3-0-3-3-0-3$ \\
\hline Habip Bairak & Chemical tanker & 8400 & 123.6 & $1^{\text {st }}$ jetty & $3-0-3-3-0-3$ \\
\hline Sichem Singapore - I & Chemical tanker & 13,141 & 128.6 & $2^{\text {nd }}$ jetty & $3-0-2-2-0-3$ \\
\hline Sichem Singapore - II & Chemical tanker & 13,141 & 128.6 & $1^{\text {st }}$ jetty & $3-0-2-2-0-3$ \\
\hline RC Behar & Chemical tanker & 5600 & 107.6 & $2^{\text {nd }}$ jetty & $3-0-2-2-0-3$ \\
\hline Castillo de Trujillo & Chemical tanker & 30,583 & 182.1 & $2^{\text {nd }}$ jetty & $4-0-3-3-0-4$ \\
\hline Nave Sextans & Chemical tanker & 51,200 & 183.1 & $2^{\text {nd }}$ jetty & $4-0-2-2-0-4$ \\
\hline Acacia Noir & Chemical tanker & 5895 & 105.5 & San Diego Dock & $2-0-1-1-0-2$ \\
\hline Banda Sea & Oil tanker & 105,576 & 237.7 & $3^{\text {rd }}$ jetty & $4-2-2-2-2-4$ \\
\hline Nissos Serifos & Oil tanker & 115,500 & 249.0 & $3^{\text {rd }}$ jetty & $4-2-2-2-2-4$ \\
\hline SKS Saluda & Oil tanker & 159,438 & 274.2 & $3^{\text {rd }}$ jetty & $4-2-2-2-2-4$ \\
\hline Marianna V.V & Oil tanker & 84,999 & 239.0 & $3^{\text {rd }}$ jetty & $4-2-2-2-2-4$ \\
\hline Eems Exe & General cargo & 3800 & 88.6 & San Diego Dock & $2-0-1-1-0-2$ \\
\hline Esky & General cargo & 3675 & 88.2 & San Diego Dock & $2-0-1-1-0-2$ \\
\hline
\end{tabular}




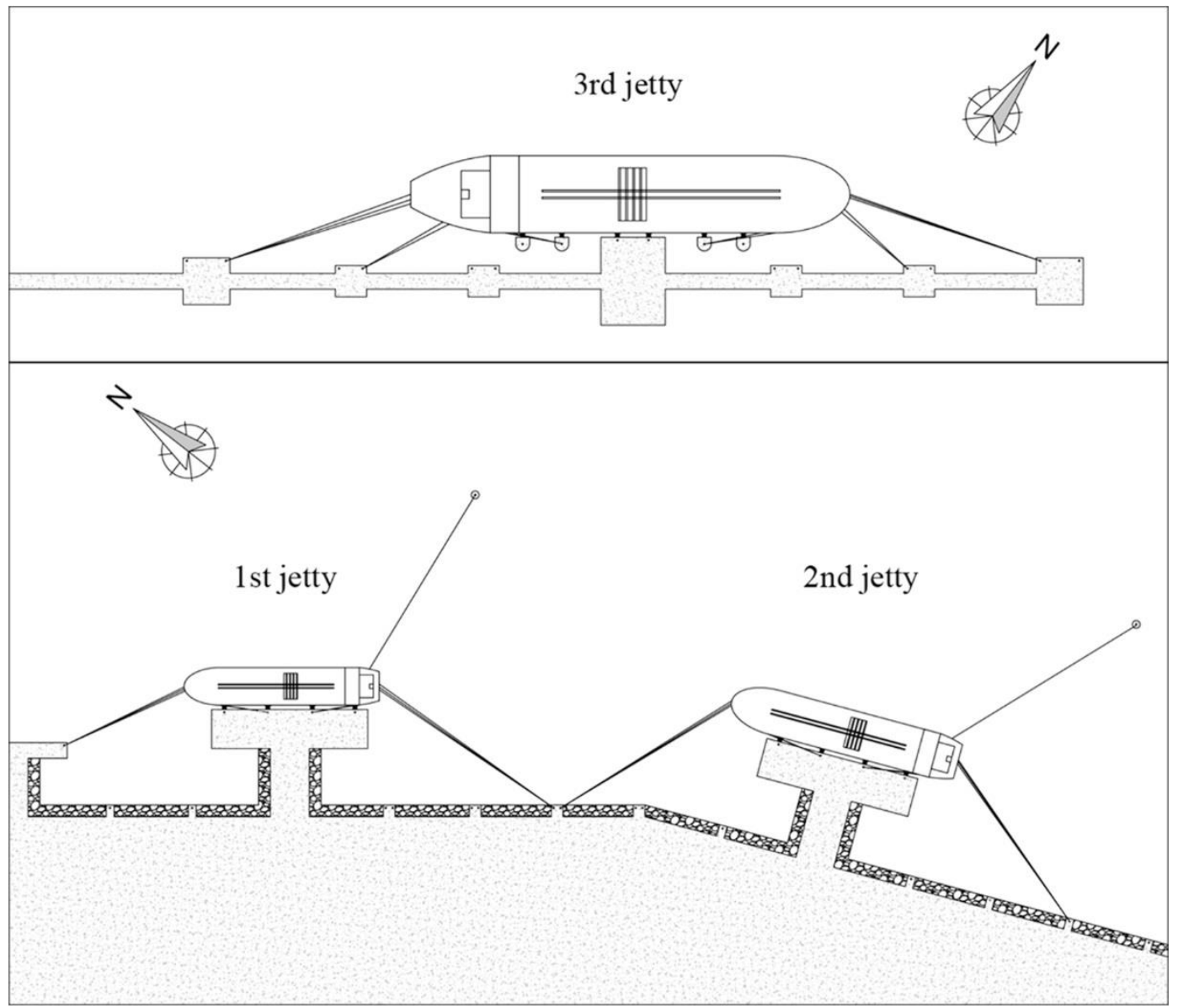

Fig. 3. Schematic representation of positions and the mooring arrangement employed in each jetty of the oil terminal.

In line with the aim of the study, selected vessels were monitored under adverse weather conditions, i.e., during situations of yellow meteorological alert according to the forecast criteria of the Port Authority of A Coruña (Table 2).

Table 2. Meteorological alert thresholds applicable to A Coruña port facilities.

\begin{tabular}{llll}
\hline & \multicolumn{3}{l}{ Meteorological alert levels } \\
\cline { 2 - 4 } Parameters & Green & Yellow & Red \\
\hline & & & \\
Significant wave height $H_{s}(\mathrm{~m})$ & $<3.5$ & $\geq 3.5$ & $\geq 7.0$ \\
Wind speed $W_{s}(\mathrm{~km} / \mathrm{h})$ & $<45$ & $\geq 45$ & $\geq 70$ \\
\hline
\end{tabular}


Table 3 presents the worst concomitant maritime conditions (significant wave height $H_{s}$, peak wave period $T_{p}$, and wind speed $W_{s}$ ) registered outside the port during the monitoring period of each vessel. These data were obtained from the official Spanish wave propagation network (Puertos del Estado, Autoridad Portuaria de A Coruña, 2017). This network provides time series of wave parameters from the real-time propagation of data measured by the outer network of wave buoys of the Spanish National Port Authority "Puertos del Estado," to points of interest on the coast. In this work, data from the propagation point CORUÑ $\left(43^{\circ} 24^{\prime} 48^{\prime \prime} \mathrm{N} 08^{\circ} 23^{\prime} 00^{\prime \prime} \mathrm{W}\right)$ located $4.8 \mathrm{~km}$ off the main breakwater of the inner port of A Coruña were used.

Table 3. Worst concomitant maritime conditions (significant wave height $H_{s}$, peak wave period $T_{p}$, wave direction $\mathrm{Dir}$ (North direction $=0^{\circ}$ ) and average wind speed $W_{s}$ ) registered outside the port during the monitoring period of each vessel

\begin{tabular}{|c|c|c|c|c|c|c|}
\hline \multirow{2}{*}{ Ship name } & \multirow{2}{*}{ Type } & \multirow{2}{*}{ Mooring location } & \multicolumn{4}{|c|}{ Worst maritime conditions } \\
\hline & & & $H_{s}(\mathrm{~m})$ & $T_{p}(\mathrm{~s})$ & $\operatorname{Dir}\left(^{\circ}\right)$ & $W_{s}(\mathrm{~km} / \mathrm{h})$ \\
\hline Scali del Teatro - III & Gas tanker & $1^{\text {st }}$ jetty & 4.9 & 15.1 & 315.0 & 24.8 \\
\hline Scali Reali & Gas tanker & $2^{\text {nd }}$ jetty & 2.5 & 12.8 & 325.0 & 12.8 \\
\hline Scali del Teatro - I & Gas tanker & $2^{\text {nd }}$ jetty & 4.1 & 10.7 & 326.0 & 43.2 \\
\hline Maingas & Gas tanker & $2^{\text {nd }}$ jetty & 4.9 & 16.0 & 310.0 & 25.7 \\
\hline Matthew & Gas tanker & $2^{\text {nd }}$ jetty & 1.1 & 11.4 & 323.0 & 8.8 \\
\hline Scali del Teatro - II & Gas tanker & $2^{\text {nd }}$ jetty & 1.8 & 15.0 & 320.0 & 22.2 \\
\hline Habip Bairak & Chemical tanker & $1^{\text {st }}$ jetty & 3.7 & 12.8 & 302.0 & 12.8 \\
\hline Sichem Singapore - I & Chemical tanker & $2^{\text {nd }}$ jetty & - & - & - & 26.5 \\
\hline Sichem Singapore - II & Chemical tanker & $1^{\text {st }}$ jetty & 3.7 & 17.6 & 319.0 & 28.1 \\
\hline RC Behar & Chemical tanker & $2^{\text {nd }}$ jetty & 2.3 & 12.6 & 300.0 & 14.3 \\
\hline Castillo de Trujillo & Chemical tanker & $2^{\text {nd }}$ jetty & 2.9 & 12.5 & 321.0 & 10.4 \\
\hline Nave Sextans & Chemical tanker & $2^{\text {nd }}$ jetty & 3.9 & 15.6 & 314.0 & 35.7 \\
\hline Acacia Noir & Chemical tanker & San Diego Dock & - & - & - & 60.4 \\
\hline Banda Sea & Oil tanker & $3^{\text {rd }}$ jetty & 3.9 & 14.9 & 308.0 & 25.6 \\
\hline Nissos Serifos & Oil tanker & $3^{\text {rd }}$ jetty & - & - & - & 52.9 \\
\hline SKS Saluda & Oil tanker & $3^{\text {rd }}$ jetty & 2.7 & 12.9 & 311.0 & 5.3 \\
\hline Marianna V.V & Oil tanker & $3^{\text {rd }}$ jetty & 1.0 & 14.0 & 308.0 & 4.3 \\
\hline Eems Exe & General cargo & San Diego Dock & - & - & - & 45.7 \\
\hline Esky & General cargo & San Diego Dock & 1.8 & 13.7 & 334.0 & 37.3 \\
\hline
\end{tabular}

\subsection{Analysis of vessel motions}

A moored vessel has six degrees of freedom, divided into three rotations and three translations. Roll, pitch, and yaw are the rotations around the longitudinal, transverse, and vertical axes of the ship, respectively, and surge, sway, and heave are the corresponding translations in these axes.

In this work, five of these six motions were analyzed (roll, pitch, yaw, surge, and heave) using two different methodologies. An inertial measurement unit (IMU) integrated by three different sensors (gyroscopes, accelerometers, and magnetometers) was used to study angular motions. This device was installed inside the bridge of each monitored vessel (Fig. 4) allowing a continuous recording of roll, pitch, and yaw with a sampling rate of $4 \mathrm{~Hz}$. Details about the calibration process of the measurement technique can be found in the study by Figuero et al. (2018b). 


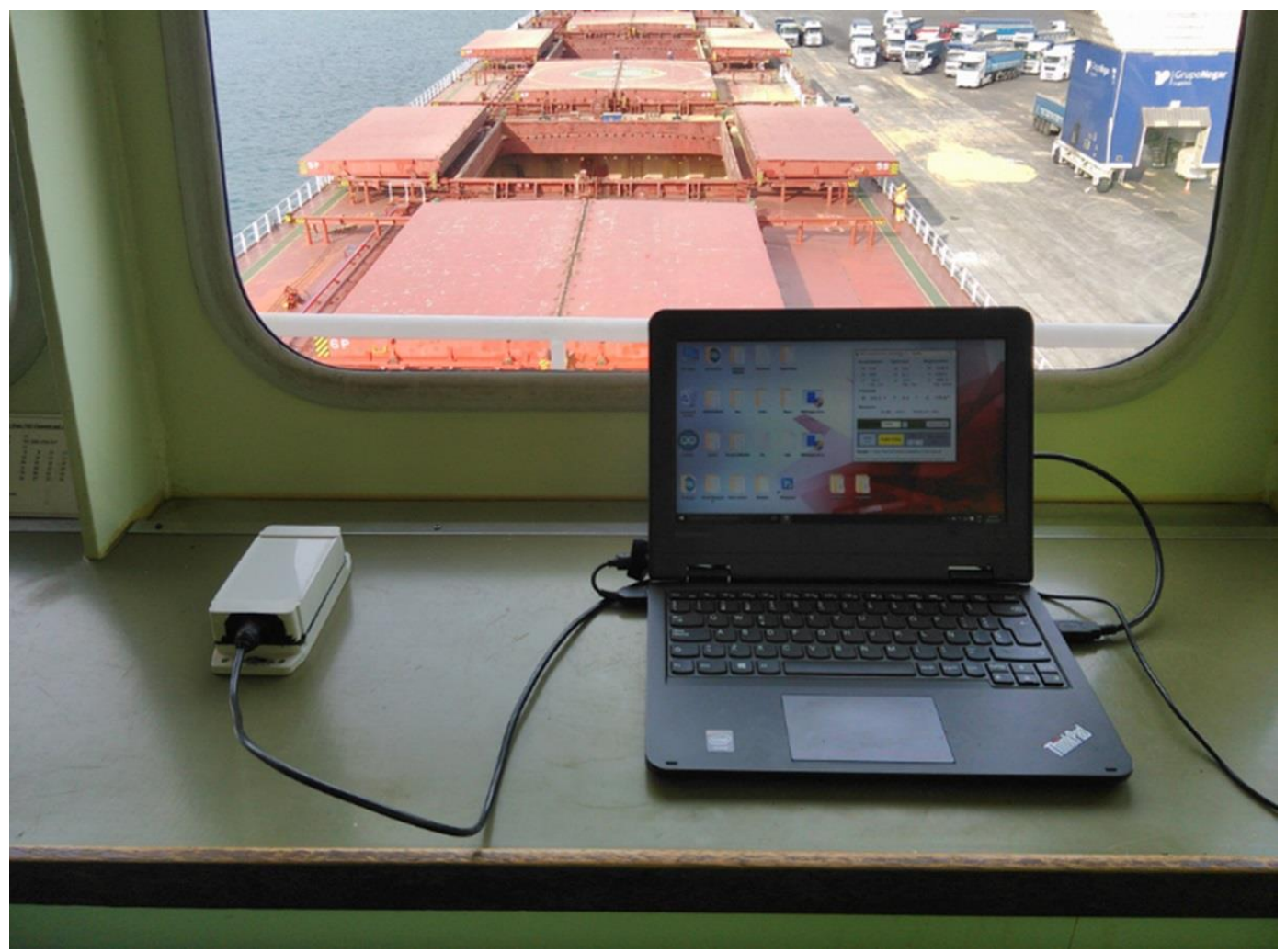

Fig. 4. IMU installed inside the vessel.

The analysis of surge and heave movements was carried out using image tracking techniques. To this end, two high resolution digital cameras were installed in front of the stern and bow of each vessel (Fig. 5), taking images with a frequency of $1 \mathrm{~Hz}$. These images were processed using a block-matching algorithm to obtain heave and surge motions. Several control points were selected and analyzed in the field of view of cameras. This strategy has also been applied in other works such as that of Figuero et al. (2018a), where the procedure is explained in detail. This technique is one of the most utilized tool for estimating movements of objects in different fields (Robertson et al., 2014; Xu et al., 2015). 


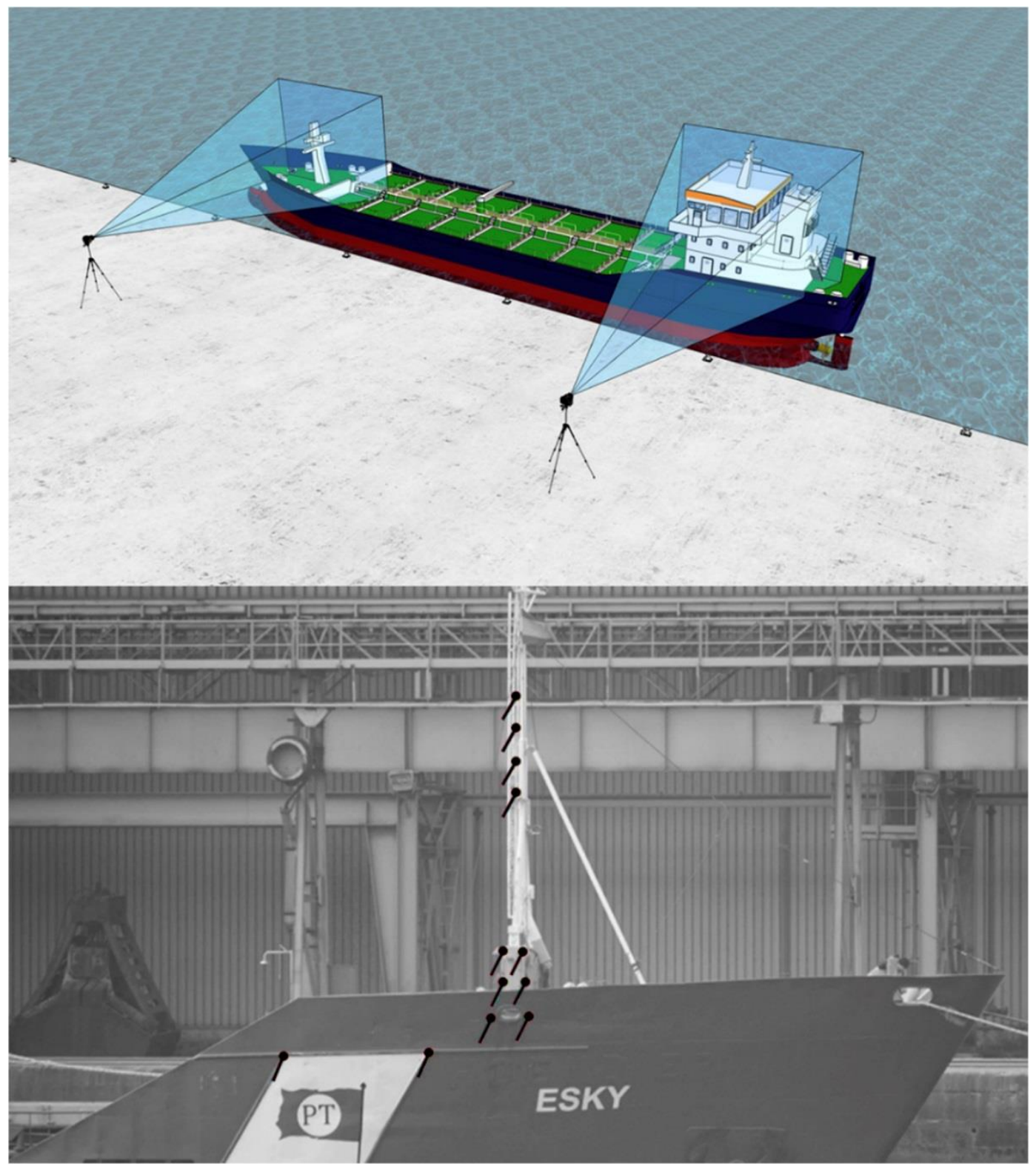

Fig. 5. Image acquisition scheme and layout of cameras on the dock (top image). Output of the bow camera of Esky general cargo ship. Selected control points and corresponding displacement vectors are represented in black marks (bottom image).

Using the synchronized combination of both methodologies (IMU and cameras), the time series of angular motions $\left(\theta_{\text {roll }}(t), \theta_{\text {pitch }}(t)\right.$, and $\left.\theta_{\text {yaw }}(t)\right)$ and displacements $\left(\delta_{\text {heave }}(t)\right.$ and $\left.\delta_{\text {surge }}(t)\right)$ are obtained. Fig. 6 shows a $1 \mathrm{~h}$ sample of each analyzed motion. 

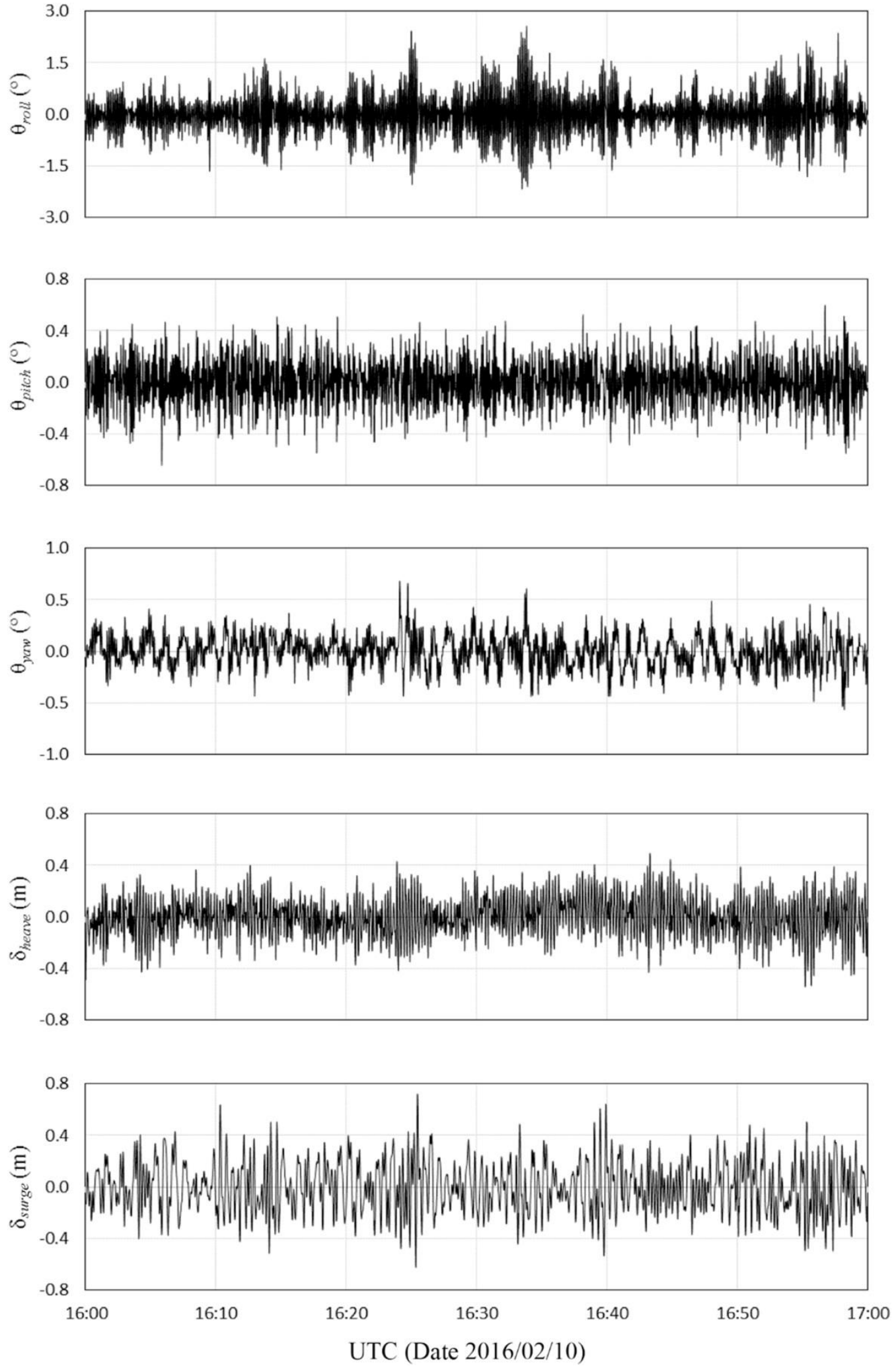

Fig. 6. A $1 \mathrm{~h}$ duration sample of motion time series recorded during the cargo operation of a representative vessel. 
For safety reasons, in facilities such as oil terminals, the use of conventional laser devices such as laser distance meters employed by the research group to determine sway movements in similar projects (Peña et al., 2017) are not allowed. Thus, the analysis of this motion could not be addressed in this work.

\subsection{Data analysis}

The analysis of motion time series was based on a zero crossing technique, having as reference the initial position of the ship. A peak-to-peak criterion was applied to each movement to obtain their amplitudes (PIANC, 1995): $A_{i}\left({ }^{\circ}\right)$ for rotations and $L_{i}(\mathrm{~m})$ for translations.

The entire time series were split into blocks of $1200 \mathrm{~s}$ duration, obtaining the maximum motion amplitude $\left(A_{\max }\right.$ or $\left.L_{\max }\right)$, mean motion amplitude $\left(A_{m}\right.$ or $\left.L_{m}\right)$, and significant motion amplitude $\left(A_{s}\right.$ or $L_{s}$ ) calculated as the average of the highest third of each block.

For rotations:

$A_{s}\left({ }^{\circ}\right)=\frac{1}{N / 3} \sum_{i=1}^{N / 3} A_{i}$

For displacements:

$L_{s}(m)=\frac{1}{N / 3} \sum_{i=1}^{N / 3} L_{i}$

Additionally, the maximum, mean, and significant amplitudes of the entire measurement period were obtained for each oscillation.

The registered values of movements were compared with the maximum values of the safe working conditions proposed by the Spanish standard ROM 2.0-11 and the PIANC (1995) (Fig. 7).

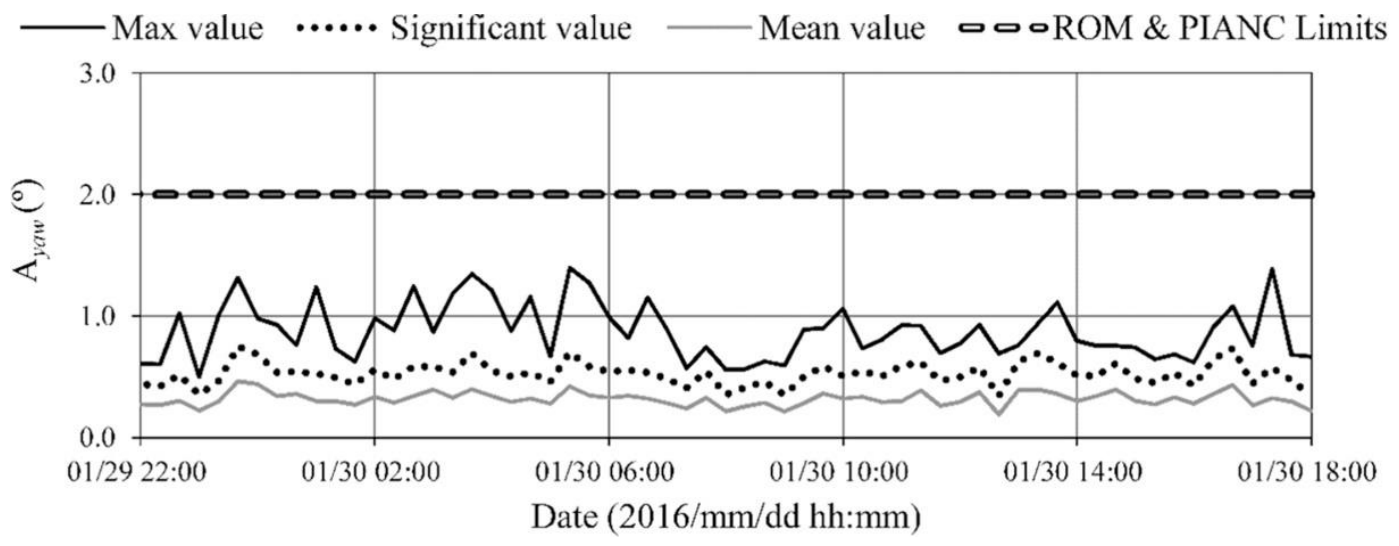

Fig. 7. Maximum, significant, and mean amplitudes of yaw motion of a representative vessel during the cargo operation. 
These thresholds were selected among those recommended by both publications depending on the ship type and cargo handling equipment. In this work, the same limiting motion criterion was applied to gas and chemical tankers because both ship categories had similar dimensions and used the same cargo equipment.

Table 4, Table 5 present the motion amplitude thresholds applied to each ship type.

Table 4. PIANC (PIANC, 1995) maximum recommended motion amplitudes for safe working condition.

\begin{tabular}{lllllll}
\hline Ship Type & Cargo handling equipment & Roll $\left(^{\circ}\right)$ & Pitch $\left(^{\circ}\right)$ & Yaw $\left({ }^{\circ}\right)$ & Heave $(\mathrm{m})$ & Surge $(\mathrm{m})$ \\
\hline \multirow{3}{*}{ Oil tankers } & Loading arms & - & - & - & - & 3.0 \\
Gas tankers & Loading arms & 2 & 2 & 2 & - & 2.0 \\
General cargo & - & 5 & 2 & 3 & 1.0 & 2.0 \\
\end{tabular}

Table 5. ROM 2.0-11 (Puertos del Estado, 2011) maximum recommended motion amplitudes for safe working condition.

\begin{tabular}{lllllll}
\hline Ship Type & Cargo handling equipment & Roll $\left(^{\circ}\right)$ & Pitch $\left(^{\circ}\right)$ & Yaw $\left(^{\circ}\right)$ & Heave $(\mathrm{m})$ & Surge $(\mathrm{m})$ \\
\hline & & & & & & \\
Oil tankers & Loading arms & - & - & - & - & 7.0 \\
Gas tankers & Loading arms & 2 & 2 & 2 & - & 4.0 \\
General cargo & - & 5 & 2 & 3 & 1.0 & 2.0 \\
\end{tabular}

Additionally, the time series were analyzed in the frequency domain. The power spectrum of the complete record of each movement was obtained by the application of a fast Fourier transform. Data were divided into a long-period component (LF) and a short-period component (SF), using a threshold frequency of $0.04 \mathrm{~Hz}$ (oscillation period of $25 \mathrm{~s}$ ). For each frequency band, the associated peak period was obtained $\left(T_{L F}\right.$ and $\left.T_{S F}\right)$ and the most energetic was also identified. This information allowed determining which frequency band was more relevant for each motion (Fig. 8). 

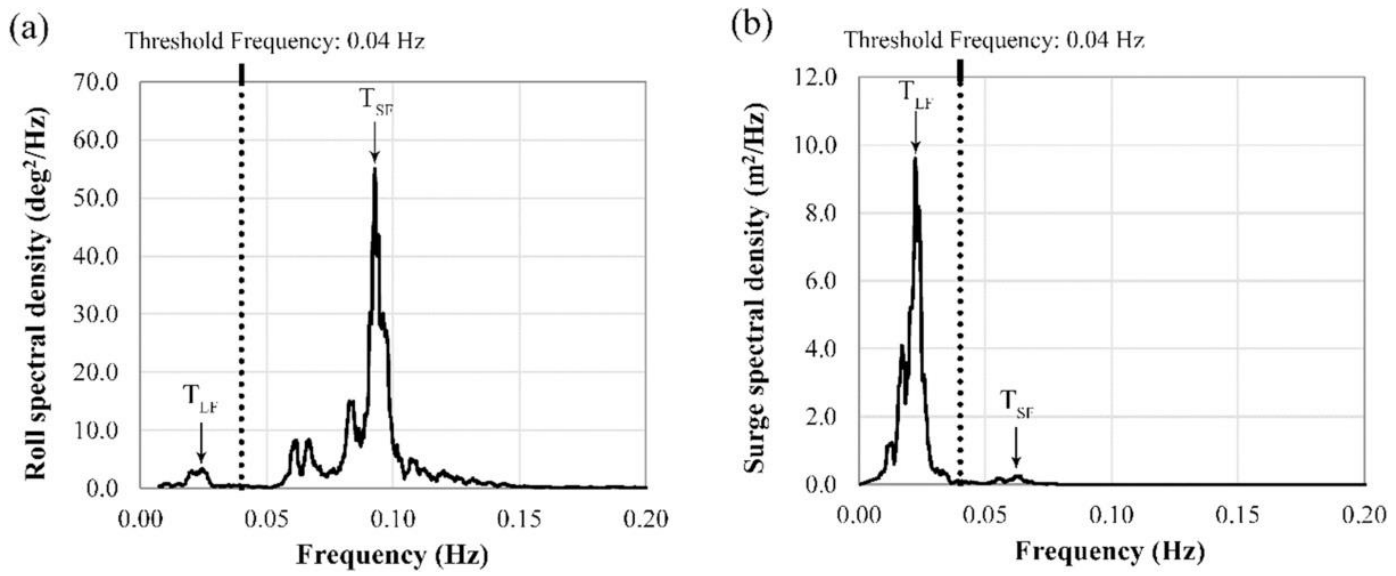

Fig. 8. Sample of the power spectrum of (a) roll and (b) surge motions of a representative vessel.

\section{Results and discussion}

In this study, 19 vessels were monitored to analyze the operational conditions in the inner port of A Coruña (oil terminal facilities and San Diego dock) under adverse wave climate conditions (weather alert situations). Two different methodologies (IMU and cameras) were used to characterize five of the six degrees of freedom of a moored ship. Furthermore, relations between vessel motions and their meteorological forcings were analyzed (significant wave height $H_{s}$ and peak wave period $T_{p}$ outside the port).

\subsection{Vessel movements and comparison with existing operational thresholds}

Roll and yaw registered the largest amplitudes of angular motions, with a maximum of $A_{\max }^{\text {roll }}=10.3^{\circ}$ and $A_{\max }^{\text {roll }}=5.4^{\circ}$, respectively (Scali del Teatro gas tanker). During the field campaign, 13 of the 19 monitored ships experienced amplitudes of roll that exceeded both the PIANC (1995) and ROM 2.0-11 thresholds (Table 6). It should be noted that in six of these vessels, not only the maximum values of roll exceeded the limits established in these publications, but also the significant values, with no downtime registered (Table 6). 
Table 6. Maximum and significant amplitude of angular motions recorded during the entire measurement period and motion limiting criteria for each vessel.

\begin{tabular}{|c|c|c|c|c|c|c|c|c|c|c|c|c|c|}
\hline \multirow{2}{*}{ Type } & \multirow{2}{*}{ Ship Name } & \multicolumn{2}{|c|}{ Roll ( $\left(^{\circ}\right)$} & \multicolumn{2}{|c|}{$\operatorname{Pitch}\left(^{o}\right)$} & \multicolumn{2}{|c|}{ Yaw $\left(^{\circ}\right)$} & \multicolumn{3}{|c|}{ PIANC Limits $\left(^{\circ}\right)$} & \multicolumn{3}{|c|}{ ROM Limits $\left(^{\circ}\right)$} \\
\hline & & $\mathrm{A}_{\max }$ & $\mathrm{A}_{\mathrm{s}}$ & $\mathrm{A}_{\max }$ & $\mathrm{A}_{\mathrm{s}}$ & $\mathrm{A}_{\max }$ & $\mathrm{A}_{\mathrm{s}}$ & $\mathrm{A}_{\text {Roll }}$ & $\mathrm{A}_{\text {Pitch }}$ & $\mathrm{A}_{\text {Yaw }}$ & $\mathrm{A}_{\text {Roll }}$ & $\mathrm{A}_{\text {Pitch }}$ & $\mathrm{A}_{\text {Yaw }}$ \\
\hline \multirow[t]{6}{*}{ Gas tankers } & Scali del T. - III & 10.3 & 4.2 & 0.8 & 0.4 & 1.4 & 0.5 & & & 2.0 & & & \\
\hline & Scali Reali & 7.6 & 3.4 & 0.5 & 0.3 & 3.6 & 1.7 & & & 2.0 & & & \\
\hline & Scali del T. - I & 7.4 & 2.9 & 0.8 & 0.4 & 5.4 & 2.5 & & & 2.0 & & & \\
\hline & Maingas & 6.8 & 2.8 & 1.0 & 0.4 & 5.6 & 3.1 & & & 2.0 & & & \\
\hline & Matthew & 6.0 & 2.1 & 0.4 & 0.1 & 2.5 & 0.7 & & & 2.0 & & & \\
\hline & Scali del T. - II & 4.3 & 1.3 & 0.6 & 0.3 & 1.2 & 0.4 & & & 2.0 & & & \\
\hline \multirow[t]{7}{*}{ Chemical tankers } & Habip Bairak & 4.7 & 2.1 & 1.0 & 0.4 & 1.8 & 0.8 & & & 2.0 & & & \\
\hline & Sichem S. - I & 3.9 & 1.8 & 0.5 & 0.3 & 3.2 & 1.4 & & & 2.0 & & & \\
\hline & Sichem S. - II & 3.8 & 1.7 & 0.9 & 0.4 & 1.6 & 0.7 & & & 2.0 & & & \\
\hline & RC Behar & 3.3 & 1.1 & 0.4 & 0.2 & 0.6 & 0.2 & & & 2.0 & & & \\
\hline & Castillo de T. & 4.4 & 1.8 & 0.6 & 0.3 & 0.9 & 0.4 & & & 2.0 & & & \\
\hline & Nave Sextans & 3.2 & 1.4 & 0.3 & 0.1 & 1.1 & 0.5 & & & 2.0 & & & \\
\hline & Acacia Noir & 2.6 & 1.1 & 0.9 & 0.5 & 1.7 & 0.7 & & & 2.0 & & & \\
\hline \multirow[t]{4}{*}{ Oil tankers } & Banda Sea & 1.0 & 0.4 & 0.6 & 0.3 & 0.4 & 0.2 & - & - & - & - & - & - \\
\hline & Nissos Serifos & 0.7 & 0.3 & 0.2 & 0.1 & 0.2 & 0.1 & - & - & - & - & - & - \\
\hline & Marianna V.V & 0.4 & 0.2 & 0.4 & 0.2 & 0.7 & 0.2 & - & - & - & - & - & - \\
\hline & SKS Saluda & 0.6 & 0.3 & 0.2 & 0.1 & 0.6 & 0.3 & - & - & - & - & - & - \\
\hline \multirow[t]{2}{*}{ General cargo } & Eems Exe & 4.7 & 2.1 & 1.1 & 0.6 & 0.9 & 0.4 & 5.0 & 2.0 & 3.0 & 5.0 & 2.0 & 3.0 \\
\hline & Esky & 2.9 & 1.3 & 0.4 & 0.3 & 1.7 & 0.6 & 5.0 & 2.0 & 3.0 & 5.0 & 2.0 & 3.0 \\
\hline
\end{tabular}

Fig. 9, Fig. 10 show the maximum, significant, and mean amplitudes of roll motion recorded during cargo operation in two of these six vessels (Scali del Teatro - III and Scali Reali gas tankers). As can be observed, even the mean values of roll were above the limiting criteria of the recommendations during a large part of the cargo operation.

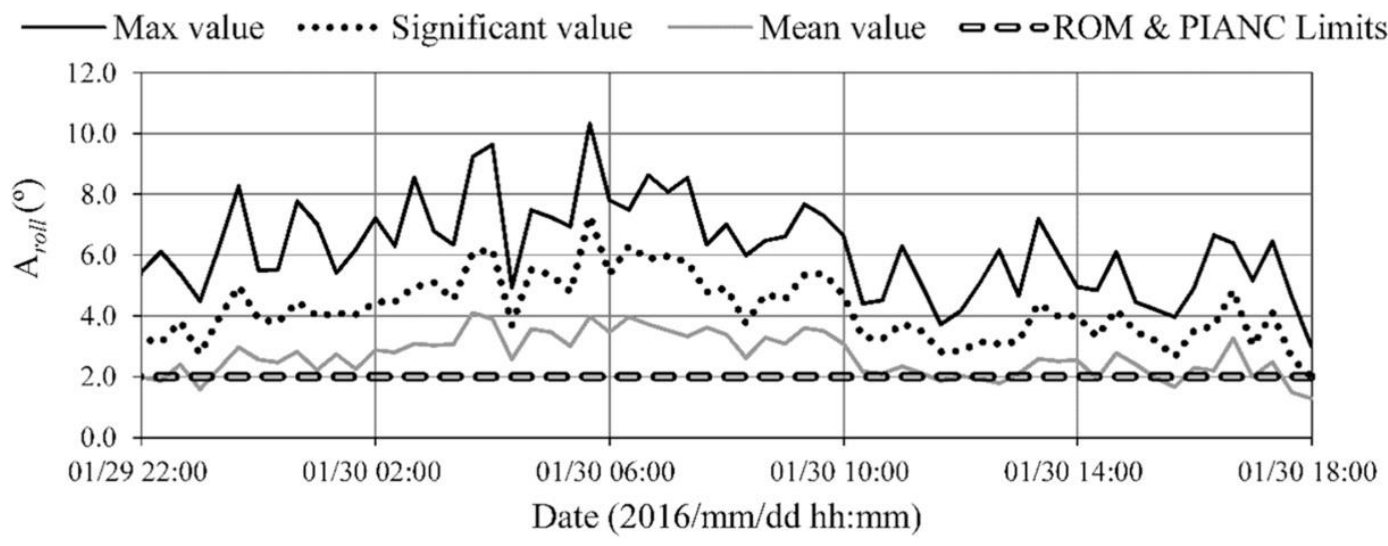

Fig. 9. Maximum, significant, and mean amplitudes of roll angular motion of Scali del Teatro - III gas tanker during cargo operation. 


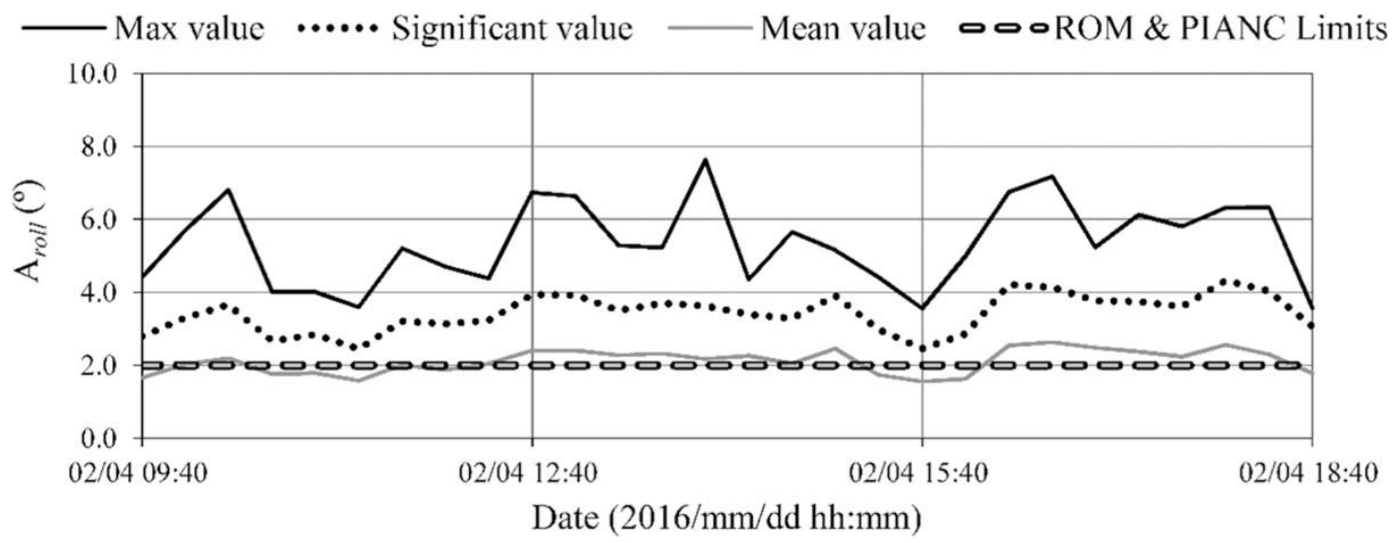

Fig. 10. Maximum, significant, and mean amplitudes of roll angular motion of Scali Reali gas tanker during cargo operation.

Regarding yaw, this behavior was also observed although less frequently than roll. In five of the analyzed vessels, the maximum yaw amplitude exceeded the proposed thresholds, and in two of them (Scali del Teatro - I and Maingas gas tankers), also the significant value (Table 6).

Pitch motion recorded the lowest amplitudes of angular movements in all analyzed vessels. Maximum and significant amplitudes of pitch reached values of $1.1^{\circ}$ and $0.6^{\circ}$, respectively (Eems Exe general cargo ship), both significantly below the limiting criteria of the recommendations (Table 6).

It is important to note that the mentioned cases in which angular movements exceeded the recommended thresholds (especially roll and yaw motions) were mainly registered by gas tankers and small chemical tankers (up to $130 \mathrm{~m}$ length) moored at the $1 \mathrm{st}$ and 2 nd jetties. In contrast, oil tankers moored at the 3rd jetty experienced the smallest motions, with amplitudes below $1^{\circ}$. Fig. 11, Fig. 12 show the maximum and significant value of each angular movement recorded by these vessels during their loading operation. As can be seen, the smallest ships have experienced considerably larger angular movements than the oil tankers, especially gas tankers, which reached extremely high values of roll and yaw. 


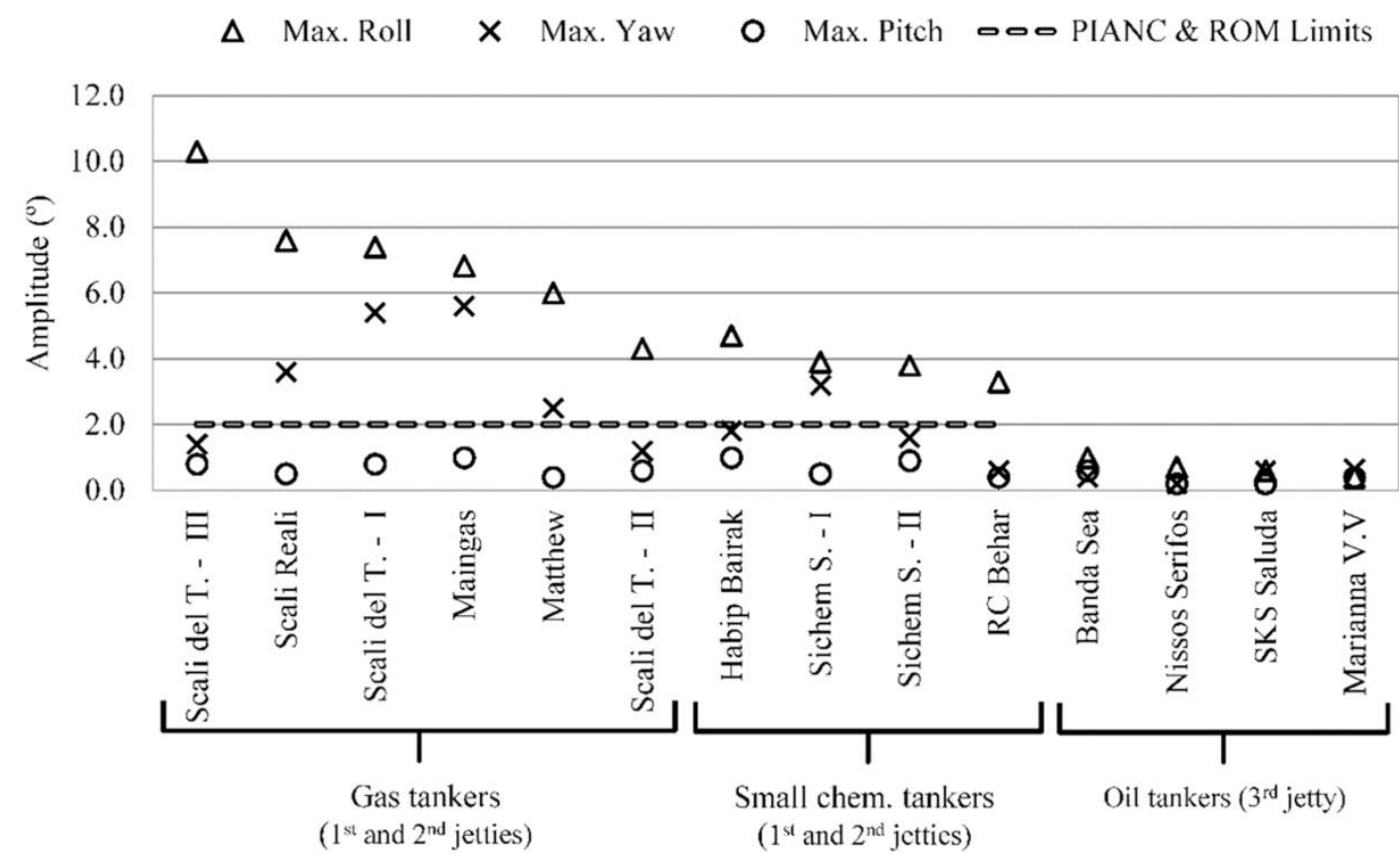

Fig. 11. Comparison between the maximum amplitudes of angular movements recorded by small gas and chemical tankers, oil tankers, and the PIANC and ROM 2.0-11 motion thresholds.

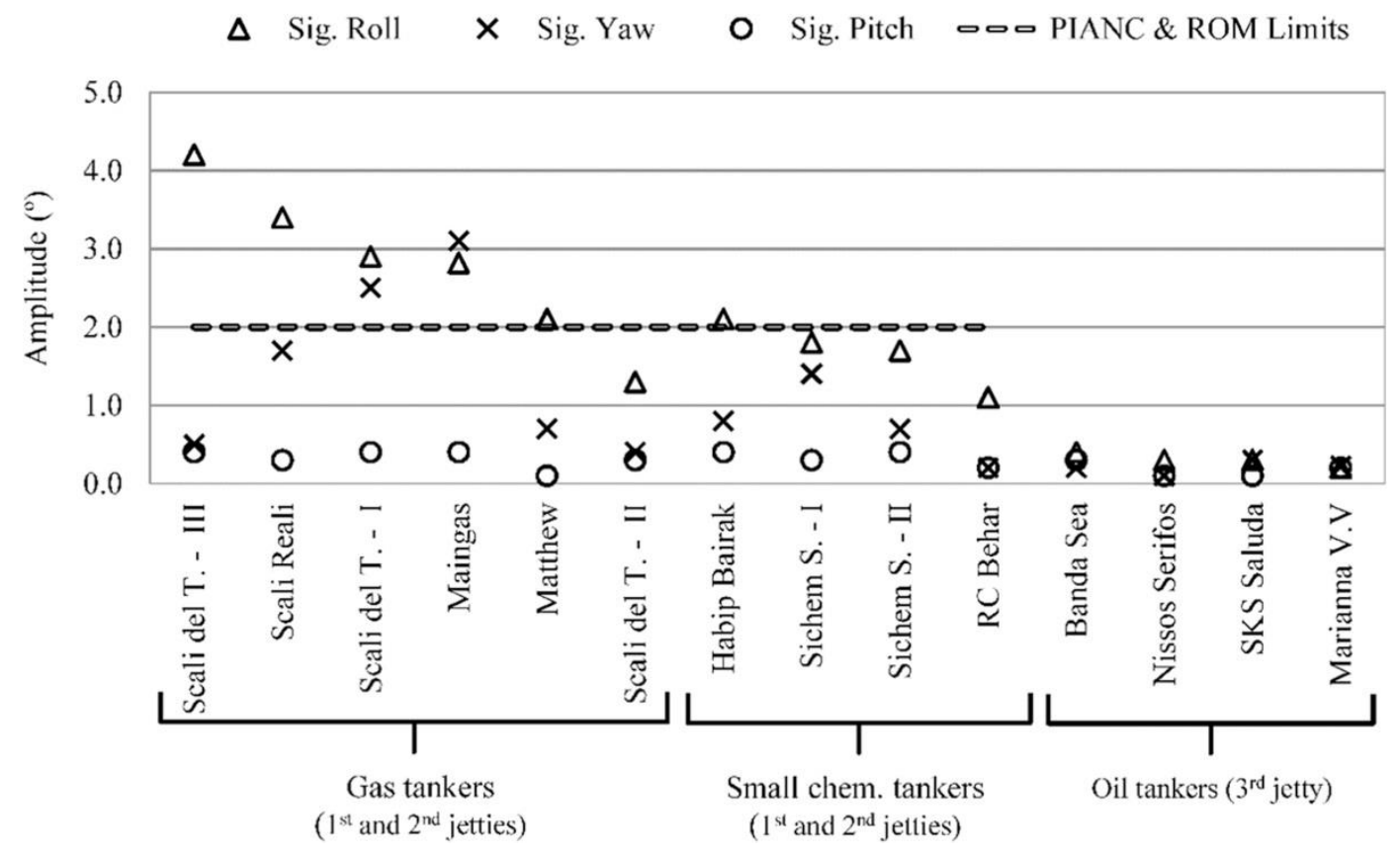

Fig. 12. Comparison between significant amplitudes of angular movements recorded by small gas and chemical tankers, oil tankers, and the PIANC and ROM 2.0-11 motion thresholds. 
The influences of maritime conditions and mooring location on the particular behavior of some vessels are analyzed in section 4.2.

As regards the linear movements, surge motion registered larger amplitudes than heave motion, especially in gas and chemical tankers (Table 7), with maximum values of $L_{\max }^{\text {surge }}=2.20 \mathrm{~m}$ (Maingas gas tanker) and $=L_{\text {max }}^{\text {heave }}=1.00 \mathrm{~m}$ (Scali del Teatro - III gas tanker), respectively.

Table 7. Maximum and significant amplitude of linear motions recorded during the entire measurement period and limiting criteria for each vessel.

\begin{tabular}{|c|c|c|c|c|c|c|c|c|c|}
\hline \multirow{2}{*}{ Type } & \multirow{2}{*}{ Ship Name } & \multicolumn{2}{|c|}{ Heave (m) } & \multicolumn{2}{|c|}{ Surge (m) } & \multicolumn{2}{|c|}{ PIANC Limits (m) } & \multicolumn{2}{|c|}{ ROM Limits (m) } \\
\hline & & $\mathrm{L}_{\max }$ & $\mathrm{L}_{\mathrm{s}}$ & $\mathrm{L}_{\max }$ & $\mathrm{L}_{\mathrm{s}}$ & $\mathrm{L}_{\text {Heave }}$ & $\mathrm{L}_{\text {Surge }}$ & $\mathrm{L}_{\text {Heave }}$ & $\mathrm{L}_{\text {Surge }}$ \\
\hline \multirow[t]{6}{*}{ Gas tankers } & Scali del T. - III & 1.00 & 0.50 & 1.55 & 0.60 & - & 2.0 & - & 4.0 \\
\hline & Scali Reali & 0.65 & 0.30 & 0.70 & 0.30 & - & 2.0 & - & 4.0 \\
\hline & Scali del T. - I & 0.60 & 0.30 & 1.20 & 0.40 & - & 2.0 & - & 4.0 \\
\hline & Maingas & 0.86 & 0.43 & 2.20 & 1.13 & - & 2.0 & - & 4.0 \\
\hline & Matthew & 0.35 & 0.20 & 0.25 & 0.12 & - & 2.0 & - & 4.0 \\
\hline & Scali del T. - II & 0.35 & 0.15 & 0.60 & 0.20 & - & 2.0 & - & 4.0 \\
\hline \multirow[t]{7}{*}{ Chemical tankers } & Habip Bairak & 0.75 & 0.35 & 1.30 & 0.5 & - & 2.0 & - & 4.0 \\
\hline & Sichem S. - I & 0.55 & 0.25 & 0.40 & 0.20 & - & 2.0 & - & 4.0 \\
\hline & Sichem S. - II & 0.45 & 0.25 & 2.00 & 0.75 & - & 2.0 & - & 4.0 \\
\hline & RC Behar & 0.40 & 0.15 & 0.55 & 0.25 & - & 2.0 & - & 4.0 \\
\hline & Castillo de T. & 0.30 & 0.10 & 1.10 & 0.45 & - & 2.0 & - & 4.0 \\
\hline & Nave Sextans & - & - & - & - & - & 2.0 & - & 4.0 \\
\hline & Acacia Noir & - & - & - & - & - & 2.0 & - & 4.0 \\
\hline \multirow[t]{4}{*}{ Oil tankers } & Banda Sea & - & - & - & - & - & 3.0 & - & 7.0 \\
\hline & Nissos Serifos & - & - & - & - & - & 3.0 & - & 7.0 \\
\hline & Marianna V.V & 0.14 & 0.05 & 0.05 & 0.03 & - & 3.0 & - & 7.0 \\
\hline & SKS Saluda & 0.20 & 0.10 & 0.15 & 0.10 & - & 3.0 & - & 7.0 \\
\hline \multirow[t]{2}{*}{ General cargo } & Esky & 0.40 & 0.20 & 1.10 & 0.45 & 1.0 & 2.0 & 1.0 & 2.0 \\
\hline & Eems Exe & 0.85 & 0.45 & 1.75 & 0.8 & 1.0 & 2.0 & 1.0 & 2.0 \\
\hline
\end{tabular}

As with angular motions, gas tankers and small chemical tankers registered the largest linear motions (Table 7). However, surge and heave amplitudes did not frequently record values above the maximum proposed in ROM 2.0-11 and PIANC (1995) for safe working conditions. Only two of the analyzed vessels (Sichem Singapore - II chemical tanker and Maingas gas tanker) registered amplitudes of surge that are close to these thresholds (Fig. 13, Fig. 14), with no downtime registered. 


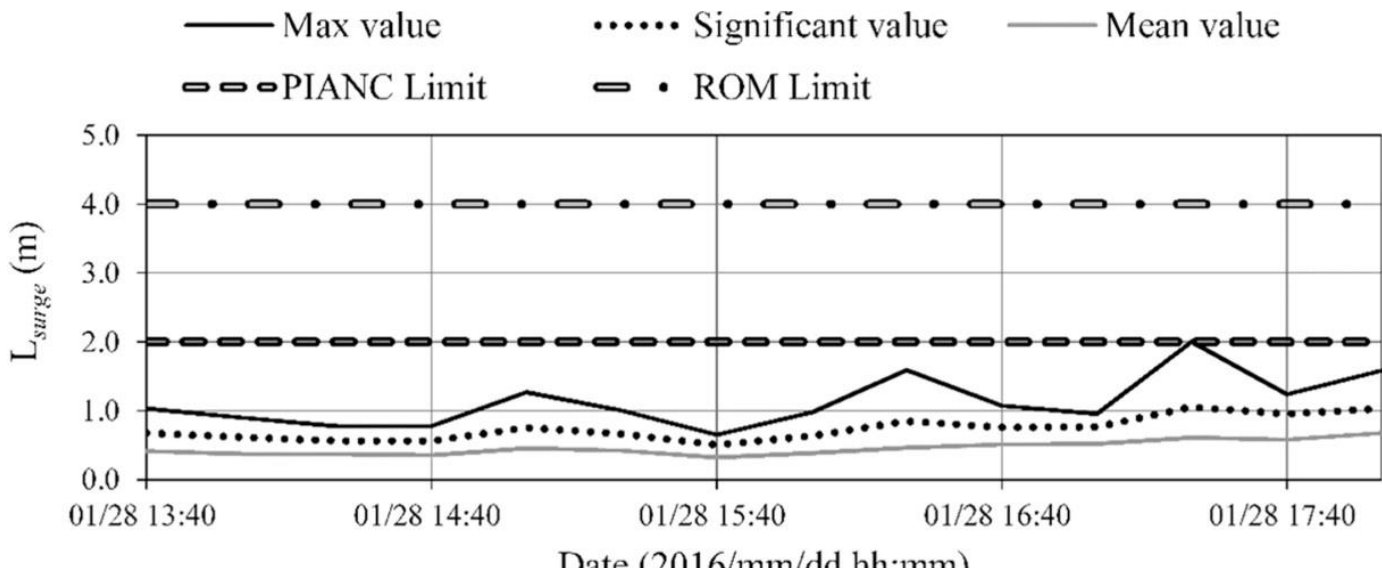

Fig. 13. Maximum, significant, and mean amplitudes of surge motion of Sichem Singapore - II chemical tanker during cargo operation.

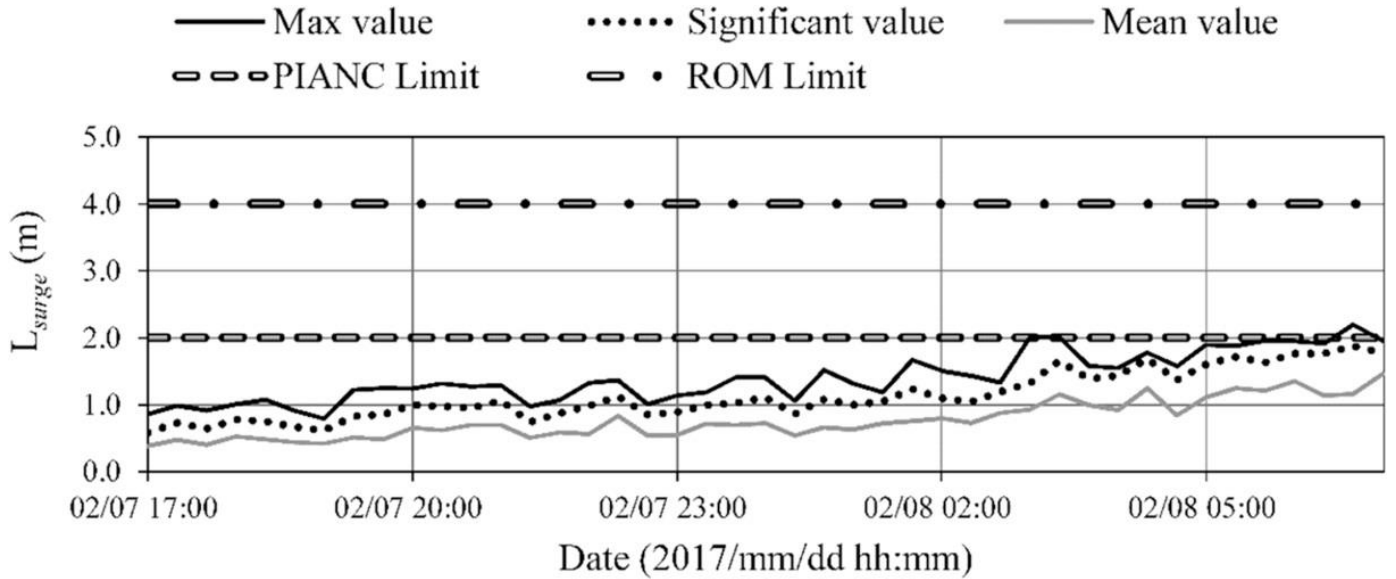

Fig. 14. Maximum, significant, and mean amplitudes of surge motion of Maingas gas tanker during cargo operation.

The previously mentioned vessels (Maingas and Scali del Teatro - III) presented a similar pattern in the vertical plane, registering the highest heave and surge movements in this study (Fig. $15 \mathrm{a}$ and $\mathrm{b}$ ). Apart from being ships of similar sizes, they were also subjected to the worst maritime conditions, with combinations of significant wave height and peak wave period outside the port from up to $4.9 \mathrm{~m}$ and $16.0 \mathrm{~s}$, respectively. This fact could explain their behavior, especially the large surge movements, with values close to the PIANC limit, related to the high peak wave period (as will be confirmed afterward). 
(a)

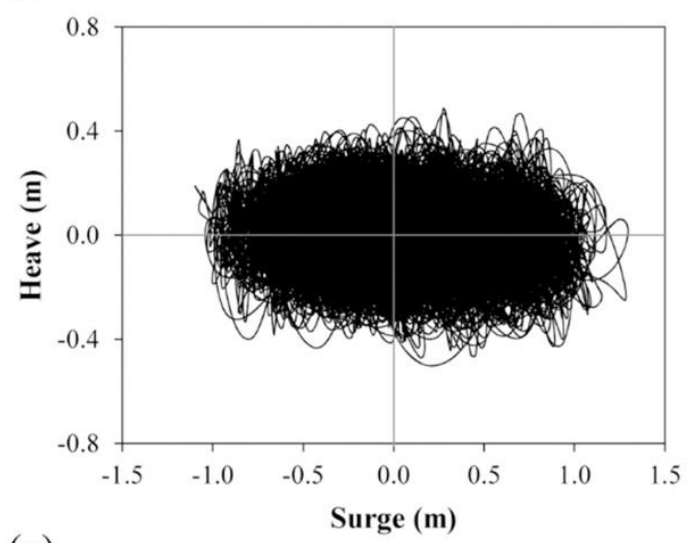

(c)

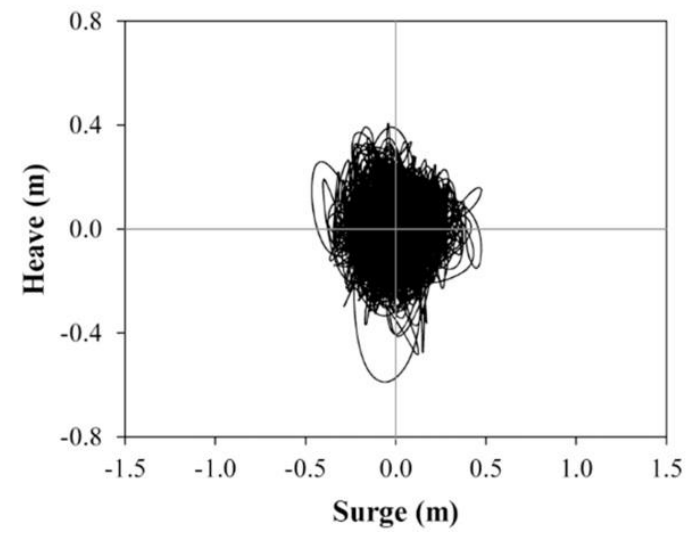

(b)

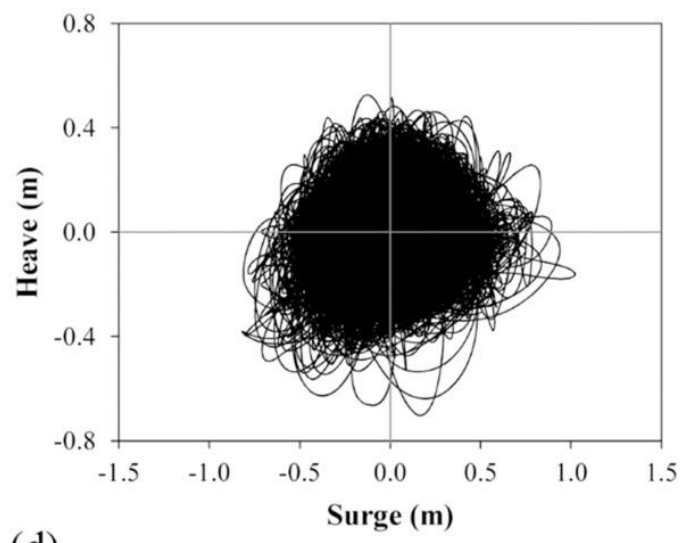

(d)

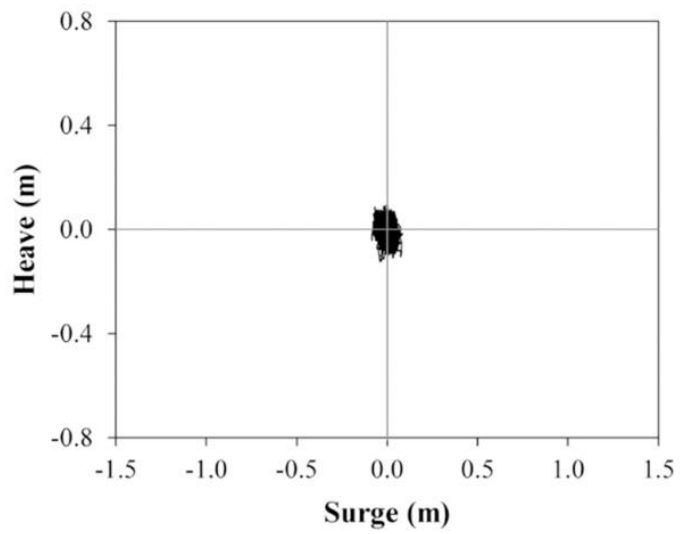

Fig. 15. Vertical plane response (surge-heave) of (a) Maingas gas tanker, (b) Scali del Teatro - III gas tanker, (c) Scali Reali gas tanker, and (d) SKS Saluda oil tanker during their cargo operation.

Fig. 15c and d shows a comparison between the vertical plane response of a gas tanker (Scali Reali) and an oil tanker (SKS Saluda), both with similar maritime conditions during their cargo operation (Table 3). As can be observed, large vessels (Fig. 15d) presented a more restricted motion pattern.

The results obtained in this study show that the angular motions are not the determining factors of downtimes in these facilities. Although roll and yaw motions recorded maximum and significant amplitudes that are larger than standard thresholds (Fig. 11), no interruptions in cargo operations were registered. Considering the vessel type (tankers and general cargo ships) and cargo handling equipment employed in the port (loading arms and conveyor belts), downtimes will probably be induced by large linear movements of moored ships (heave, surge, and sway). In this study, surge and heave motions remained below the limiting movement thresholds (Table 7). Thus, this fact may explain the absence of motion-induced operational interruptions.

Regarding the limiting criteria of the consulted standards (PIANC, 1995; Puertos del Estado, 2011), the results indicate that thresholds of angular motions are extremely restrictive for the characteristics of these vessels and port facilities. The analyzed ships were able to operate normally, although their angular motions recorded important amplitudes during operation time, especially the gas and chemical tankers moored at the 1st and 2nd jetties. It is important to note that both criteria represent generic values applicable to facilities worldwide. This general 
application makes exceptions possible. The development of similar studies carried out in different ports, including wave climate measurements inside the port, would provide comparable results that could help to particularize the limiting criteria according to the characteristics of each port facility (outer or inner ports, size of vessels, maritime conditions, etc.).

\subsection{Influence of maritime conditions and mooring location on vessel motions}

In addition, during the field campaign, sea conditions outside the port were obtained from the Spanish wave propagation network. Significant wave heights $\left(H_{s}\right)$ and peak wave periods $\left(T_{p}\right)$ of each sea state were compared with the significant amplitudes of vessel motions obtained during the same period (sea states of 1-h duration) in order to analyze the existing relations between these variables. Despite its importance on ship motions, the long wave and wind effects were not analyzed in this study due to the lack of information and reliable data both outside the port and near the mooring zones. However, the correlation between the amplitudes of each motion and the product of the wave parameters outside the port $\left(H_{s} \cdot T_{p}\right)$, which was used as an estimator coefficient of the long-period wave heights (Hiraishi et al., 1997), was determined to evaluate the influence of long waves on the vessel behavior.

Fig. 16 shows the evolution of the significant wave height outside the port compared with significant heave motions of all vessels measured during the field campaign, which are one of the least restricted movements by the mooring system. The comparison shows an acceptable relation that allows developing a more detailed analysis of the entire complex system.

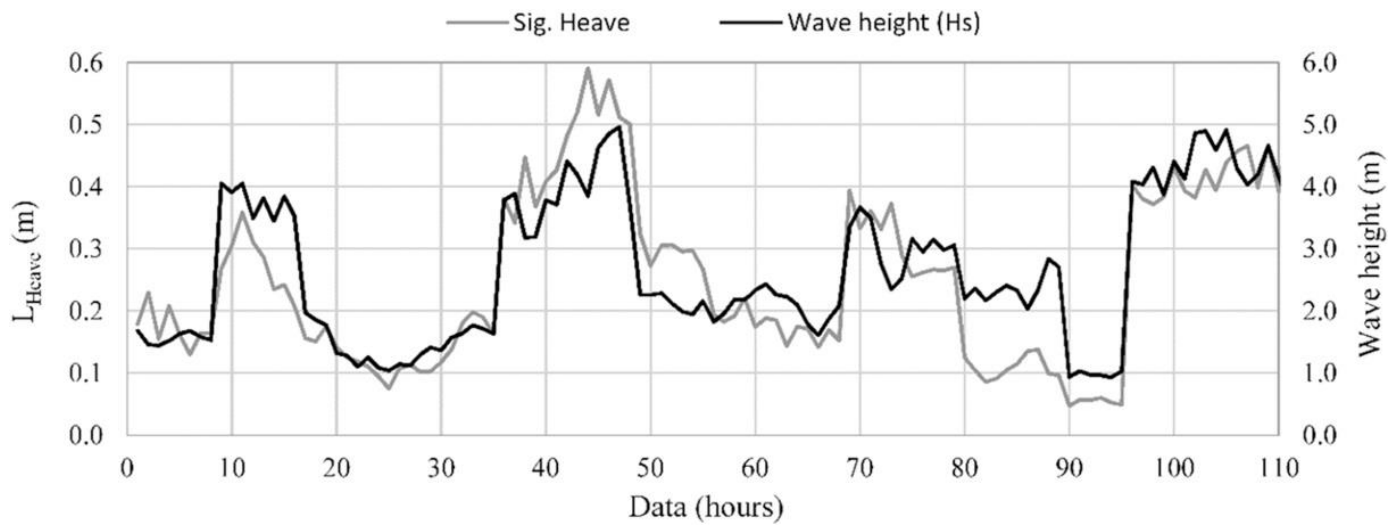

Fig. 16. Evolution of significant wave height outside the port compared with significant heave motions measured during the field campaign.

After confirming in the previous results that the vessels presented a different motion pattern (Fig. 11, Fig. 12), they were classified in two groups according to their size (small and large ships) to conduct this correlation study.

First, the relation between the movements of the gas tankers and chemical tankers from up to $130 \mathrm{~m}$ length and its forcing agents $\left(H_{s}\right.$ and $\left.T_{p}\right)$ was analyzed. This type of tankers showed a good linear relation with the wave height and the peak wave period, especially pitch, heave, and surge movements, whose correlation values are indicated in Table 8. 
Table 8. Pearson correlation coefficients of gas and small chemical tanker motions with wave height and peak wave period outside the port.

\begin{tabular}{llll}
\hline \multirow{3}{*}{ Motion } & \multicolumn{2}{l}{ Maritime condition outside the port } \\
\cline { 2 - 4 } & Hs & Tp & Hs. Tp \\
\hline & & & \\
Sig. Roll & 0.64 & 0.35 & 0.59 \\
Sig. Pitch & 0.86 & 0.66 & 0.84 \\
Sig. Yaw & 0.63 & 0.45 & 0.55 \\
Sig. Heave & 0.87 & 0.65 & 0.89 \\
Sig. Surge & 0.76 & 0.73 & 0.90 \\
& & & \\
\hline
\end{tabular}

As can be observed, the pitch and heave presented a high correlation with the wave height outside the port, exposing the influence of this parameter as stimulating of both movements as well as the less restriction imposed by the mooring system (Fig. 17a and Fig. 17b). Probably, this relation would have been even higher with the wave height data inside the port, which encourages recommending specific hydrodynamic field campaigns that can help improve the analysis. Regarding the relation to the peak wave period and the $H_{s} \cdot T_{p}$ coefficient, the surge movement presented the highest correlation values in this study (Fig. 17c and d). Results showed the influence of the peak wave period on this movement, especially the incoming waves with periods higher than $14 \mathrm{~s}$, which are related to the largest surge motions. 
(a)

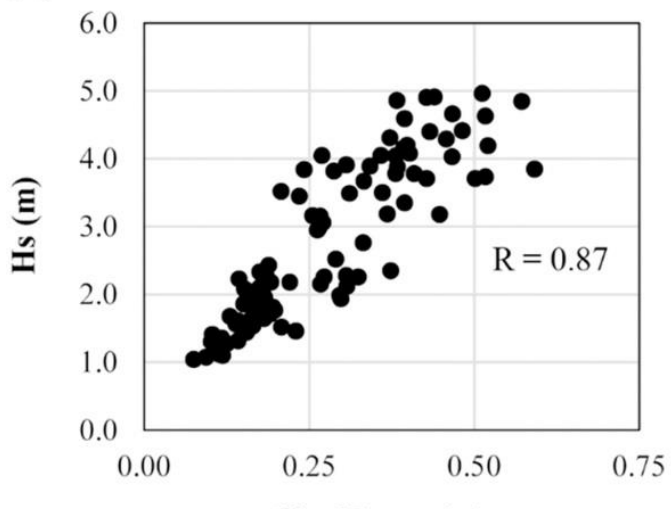

Sig. Heave (m)

(c)

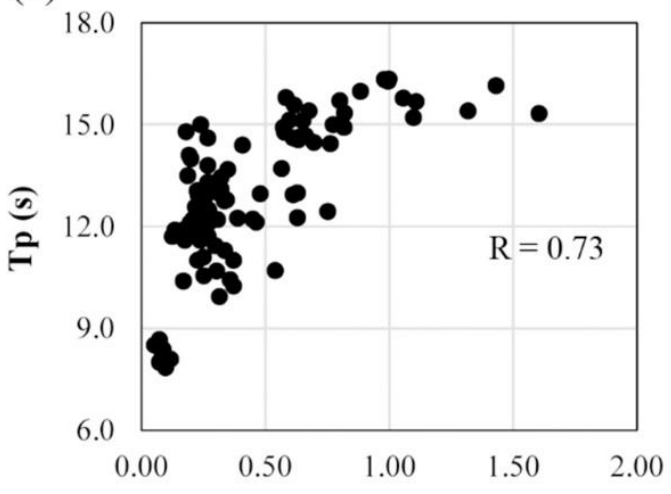

Sig. Surge (m) (b)

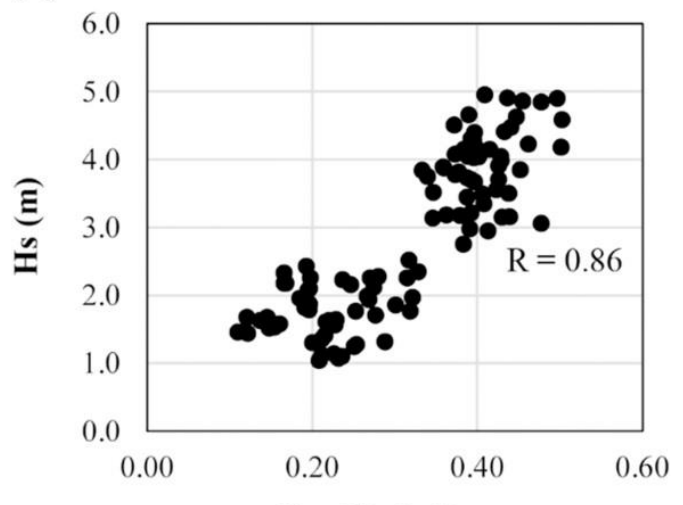

Sig. Pitch $\left({ }^{\circ}\right)$

(d)

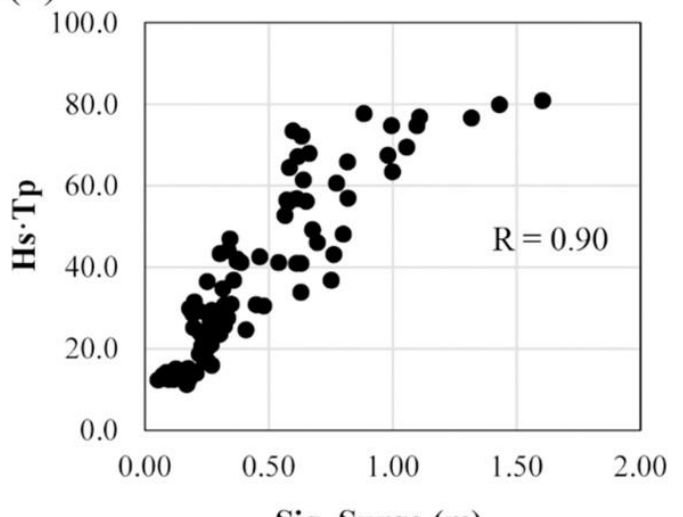

Sig. Surge (m)

Fig. 17. Scatter plots of (a)-(b) significant heave and pitch motions vs. significant wave height $\left(H_{s}\right)$ outside the port and (c)-(d) significant surge motion vs. peak wave period $\left(T_{p}\right)$ outside the port and the product $H_{s} \cdot T_{p}$ of the gas and small chemical tankers.

The dispersion patterns showed by each motion are related to the differences between the elements that composed the mooring ship system, in particular, the berthing location and mooring pretension. The mooring configuration can also play a relevant role, but not here, because nearly all ships had the same scheme (Table 1, section 3.1). Some of the vessels moored at the 1st jetty (Fig. 12, section 4.1) showed different behaviors. The Scali del Teatro - III gas tanker registered the highest value for roll, whereas the Habip Bairak and Sichem Singapore - II chemical tankers showed a lower value. These three vessels had similar yaw values and maritime conditions, and all of them were partially protected by the opposite dock; hence, the explanation of the large roll motions could be found in Scali del Teatro - III, which is the smallest.

The vessels moored at the 2nd jetty showed clear differences with the previous case. An example can be found in the behavior of the Scali Reali, Scali del Teatro - I, and Maingas gas tankers. Although they registered similar values of roll, reaching the maximum amplitudes for this location, the yaw motion of Maingas gas tanker experienced a different pattern: only this vessel showed larger significant yaw motions than roll (Fig. 12, section 4.1). While these vessels had similar sizes and the same mooring location, Maingas gas tanker was exposed to larger wave heights and periods, and a different incident wave direction of up to $15^{\circ}$ (Table 3 , section 3.1), which may justify its unique behavior. 
Despite these differences and taking into consideration the correlation values between motions and wave parameters (Table 8), three linear regression models were constructed to estimate pitch, heave, and surge responses of vessels moored at the 1 st and 2 nd jetties. Linear models were adjusted with $60 \%$ of the obtained data and were validated with the remaining $40 \%$. Eqs. (3), (4), (5) indicate the structure of each estimator and their explanatory variables.

$A_{\text {EstimatedPitch }}=b_{1} \cdot H_{s}+b_{2} \cdot T_{p}+b_{0}$

$L_{\text {EstimatedHeave }}=c_{1} \cdot H_{s}+c_{2} \cdot T_{p}+c_{0}$

$L_{\text {EstimatedSurge }}=d_{1} \cdot H_{s} \cdot T_{p}+d_{0}$

Results are shown in Table 9 and Fig. 18. As can be observed, the pitch, heave, and surge estimators provided reasonable prediction values with root mean square errors (RMSEs) of $0.056^{\circ}$, $0.057 \mathrm{~m}$, and $0.129 \mathrm{~m}$, respectively. These results, although being an initial approximation calculated with a simplified method and, without considering other factors that affect the behavior of moored vessel (size, mooring, wind, etc.), show the potential application of regression models as a useful tool for predicting risk situations and operational downtimes in ports.

Table 9. Regression model coefficients and validation parameters, R-square and root mean square error (RMSE).

\begin{tabular}{|c|c|c|c|c|c|}
\hline \multirow{2}{*}{ Model } & \multirow{2}{*}{\multicolumn{2}{|c|}{ Coefficients }} & & \multicolumn{2}{|c|}{ Validation } \\
\hline & & & & $\mathrm{R}$-square & RMSE \\
\hline \multirow[t]{2}{*}{ Pitch } & $\mathrm{b}_{0}$ & $\mathrm{~b}_{1}$ & $\mathrm{~b}_{2}$ & 0.770 & $0.056^{\circ}$ \\
\hline & -0.033 & 0.09 & 0.006 & & \\
\hline \multirow[t]{2}{*}{ Heave } & $\mathrm{c}_{0}$ & $\mathrm{c}_{1}$ & $\mathrm{c}_{2}$ & 0.801 & $0.057 \mathrm{~m}$ \\
\hline & -0.093 & 0.076 & 0.012 & & \\
\hline \multirow[t]{2}{*}{ Surge } & $\mathrm{d}_{0}$ & $\mathrm{~d}_{1}$ & & 0.762 & $0.129 \mathrm{~m}$ \\
\hline & -0.042 & 0.013 & & & \\
\hline
\end{tabular}


(a)

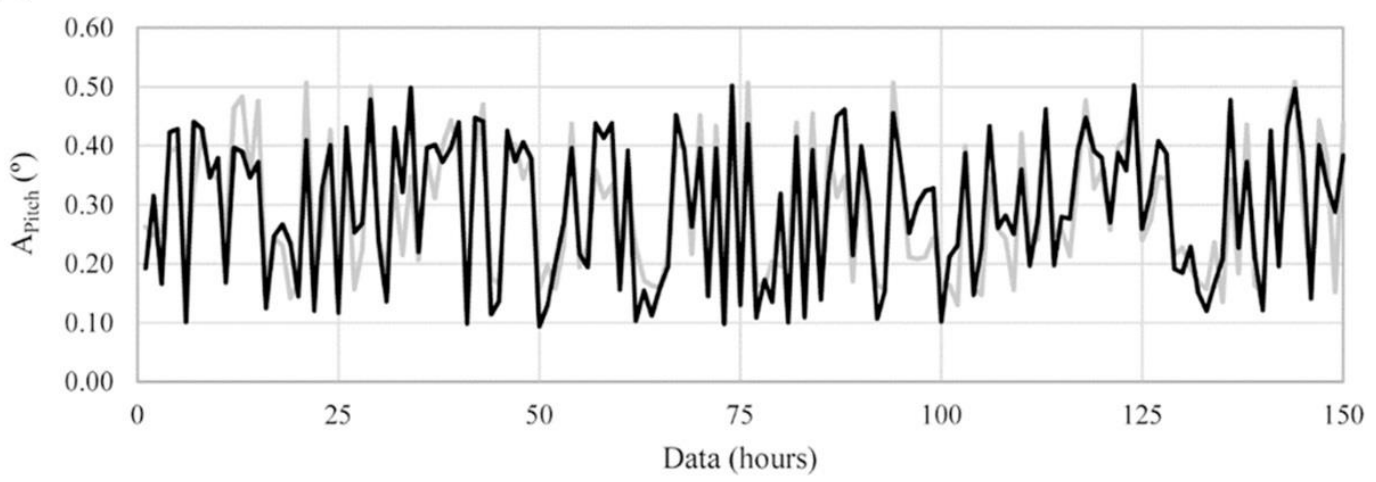

(b) - Estimated Heave - Measured Heave

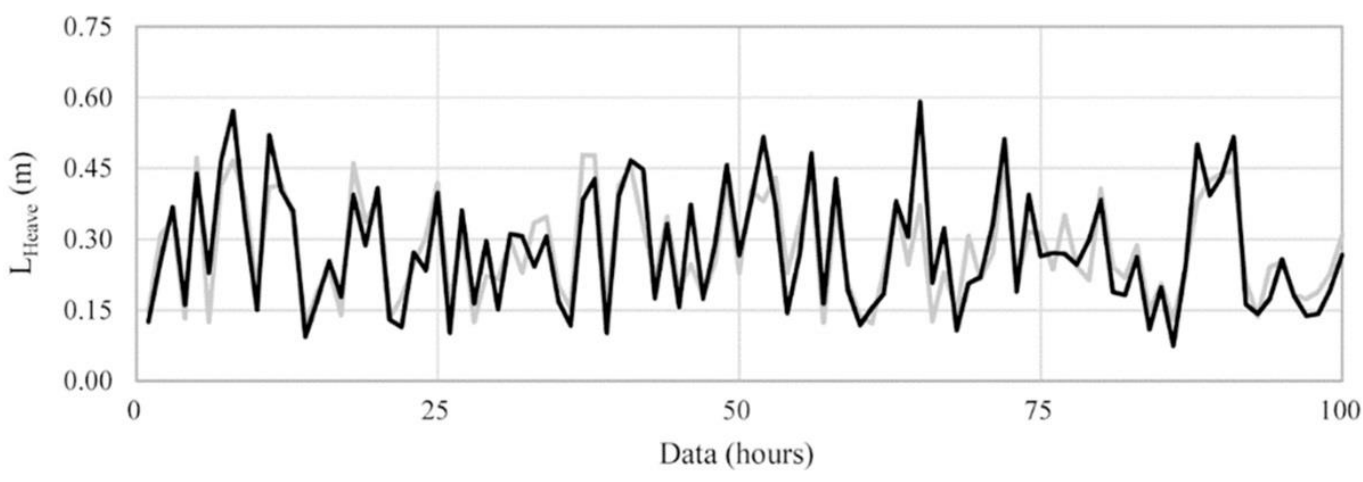

(c) - Estimated Surge —Measured Surge

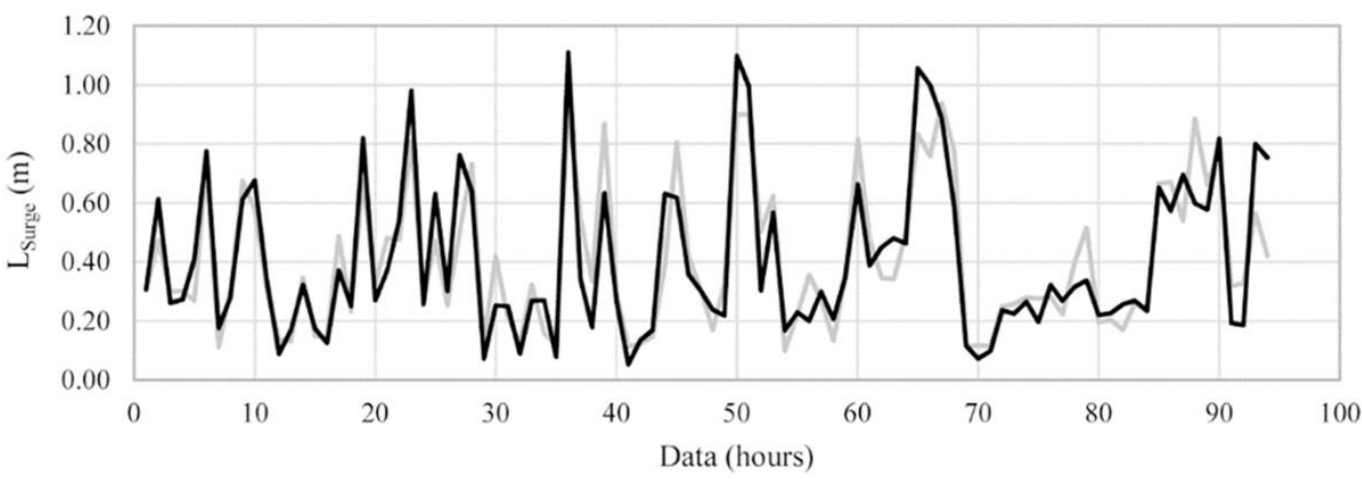

Fig. 18. Measured vs. estimated values of (a) pitch, (b) heave, and (c) surge motions.

The analysis of the relations between motions and wave parameters was repeated using the data of large vessels. The results showed lower correlation values than the ones obtained from small vessels, especially in the case of angular movements (Table 10). 
Table 10. Pearson correlation coefficients of large vessel motions with wave height and peak wave period outside the port.

\begin{tabular}{llll}
\hline \multirow{2}{*}{ Motion } & \multicolumn{2}{l}{ Maritime condition outside the port } \\
\cline { 2 - 4 } & Hs & Tp & Hs·Tp \\
\hline & & & \\
Sig. Roll & 0.17 & 0.29 & 0.19 \\
Sig. Pitch & 0.41 & 0.16 & 0.57 \\
Sig. Yaw & 0.12 & 0.03 & 0.25 \\
Sig. Heave & 0.81 & 0.62 & 0.79 \\
Sig. Surge & 0.61 & 0.56 & 0.61 \\
\hline
\end{tabular}

The linear movements showed the highest correlation values within this vessel group. However, only the heave movement presented a linear relation with the wave height outside the port (Fig. 19a). This linear relation was already shown by the small vessels.

(a)

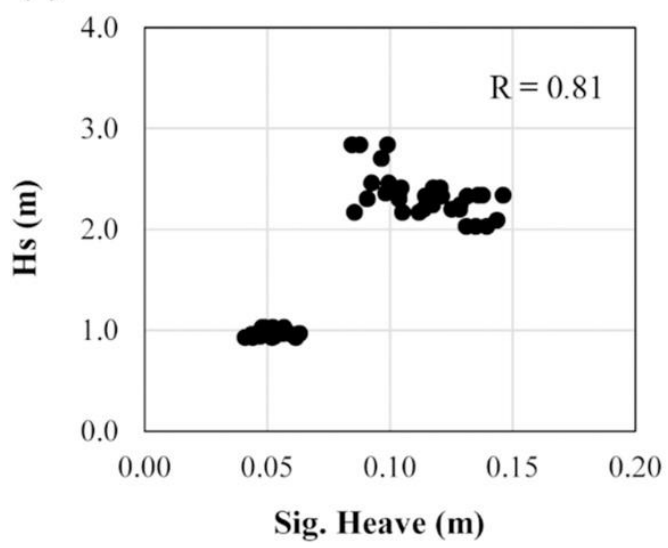

(b)

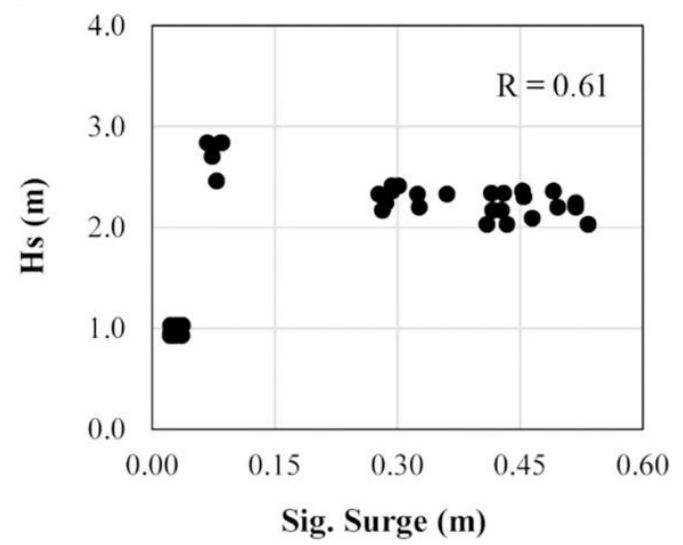

Fig. 19. Scatter plots of (a) significant heave and (b) surge motions vs. significant wave height $\left(H_{s}\right)$ outside the port of large oil tankers.

The obtained correlation values and the small number of available data did not allow the construction of reliable linear regression models for estimating large vessel motions.

The different behaviors among vessels of different sizes, in the amplitude of registered movements and its relation to the forcing agents (especially the angular movements), is due not only to the vessels size, but also to the different characteristics of the set ship-mooring system. As a clear difference from the smallest ships, the oil tankers present a mooring configuration with more lines and higher initial pretension. This restricts the vessel movement capacity, which reduces the amplitude of its movements and modifies its oscillation mode. The orientation of the mooring locations (Fig. 2), is also another determining factor of this different behavior, particularly in the case of the roll movement amplitudes registered by the small vessels (moored at the 1 st and 2 nd jetties), to which the diffracted waves affect transversely. 
Additionally, the complete time-series of each motion were analyzed in the frequency domain to obtain the peak oscillation periods of the vessels. Furthermore, the obtained results were compared with the peak wave periods provided by the Spanish wave propagation network. As previously mentioned, despite its importance on the ship motions, the long wave effects were not analyzed due to the lack of wave data with enough sampling interval to conduct a frequencydomain analysis.

In general, the power spectra showed a predominant frequency peak (Fig. 8). The oscillation periods associated with those predominant frequency peaks varied depending on the vessel motion. The obtained values were in the range of the following intervals: $T_{\text {Roll }}=6.0-17.2 \mathrm{~s}$, $T_{\text {Pitch }}=6.6-14.6 \mathrm{~s}, T_{\text {Yaw }}=10.4-68.8 \mathrm{~s}, T_{\text {Heave }}=10.8-16.8 \mathrm{~s}$, and $T_{\text {Surge }}=25.2-98.0 \mathrm{~s}$ (Table 11).

Table 11. Peak oscillation periods of each motion and average peak wave period outside the port during monitoring time.

\begin{tabular}{|c|c|c|c|c|c|c|c|}
\hline \multirow{2}{*}{ Type } & \multirow{2}{*}{ Ship Name } & \multicolumn{5}{|c|}{ Peak oscillation periods of each motion } & \multirow{2}{*}{-Avg. $T_{p_{-} \text {Buoy }}(\mathrm{s})$} \\
\hline & & $T_{\text {Roll }}(\mathrm{s})$ & $T_{\text {Pitch }}(\mathrm{s})$ & $T_{\text {Yaw }}(\mathrm{s})$ & $T_{\text {Heave }}(\mathrm{s})$ & $T_{\text {Surge }}(\mathrm{s})$ & \\
\hline \multirow[t]{6}{*}{ Gas tankers } & Scali del Teatro-III & 16.1 & 7.5 & 32.9 & 15.0 & 43.0 & 14.6 \\
\hline & Scali Reali & 14.0 & 6.2 & 14.0 & 14.1 & 49.3 & 13.0 \\
\hline & Scali del Teatro-I & 17.2 & 11.4 & 15.7 & 11.2 & 32.6 & 10.6 \\
\hline & Maingas & 11.0 & 8.6 & 47.4 & 16.5 & 68.6 & 15.6 \\
\hline & Matthew & 12.5 & 5.7 & 60.0 & 11.6 & 25.2 & 11.3 \\
\hline & Scali del Teatro-II & 16.5 & 8.3 & 40.7 & 16.8 & 37.7 & 13.2 \\
\hline \multirow[t]{7}{*}{ Chemical tankers } & Habip Bairak & 12.6 & 12.6 & 12.6 & 11.4 & 45.8 & 12.5 \\
\hline & Sichem Singapore I & 10.8 & 7.4 & 11.0 & 14.9 & 35.9 & - \\
\hline & Sichem Singapore II & 10.5 & 10.7 & 10.4 & 13.6 & 43.8 & 12.9 \\
\hline & Rc Behar & 11.9 & 12.3 & 11.6 & 13.1 & 36.6 & 12.4 \\
\hline & Castillo de Trujillo & 11.8 & 13.2 & 37.6 & 10.8 & 98.0 & 13.5 \\
\hline & Nave Sextans & 10.7 & 9.3 & 41.6 & - & - & 16.4 \\
\hline & Acacia Noir SD & 9.7 & 10.3 & 68.0 & - & - & - \\
\hline \multirow[t]{3}{*}{ Oil tankers } & Banda Sea & 11.8 & 14.6 & 11.8 & - & - & 14.9 \\
\hline & Nissos Serifos & 10.6 & 10.6 & 10.3 & - & - & - \\
\hline & SKS Saluda & 12.4 & 11.4 & 12.4 & 10.8 & 49.9 & 11.8 \\
\hline \multirow[t]{2}{*}{ General cargo } & Eems Exe & 8.0 & 6.9 & 38.5 & 13.6 & 44.6 & - \\
\hline & Esky & 6.0 & 6.6 & 37.3 & 14.3 & 42.9 & 12.2 \\
\hline
\end{tabular}

As can be observed in Table 11, vertical plane motions (roll, pitch, and heave) registered shorter oscillation periods than those of the horizontal plane (yaw and surge). These results suggested that yaw and especially surge were governed by the low-frequency band that can be excited in many ports as a consequence of long-period waves. Conversely, the short-frequency band was more relevant for roll, pitch, and heave motions, which are directly excited by shortperiod waves. This influence on the vertical plane motions was more significant in the heave motion. Not only the values of peak wave period and heave oscillation period during the monitoring time were similar, as with pitch and roll, but also a strong linear relation between both values was identified, especially in the case of gas tankers and small chemical tankers (Fig. 20). 


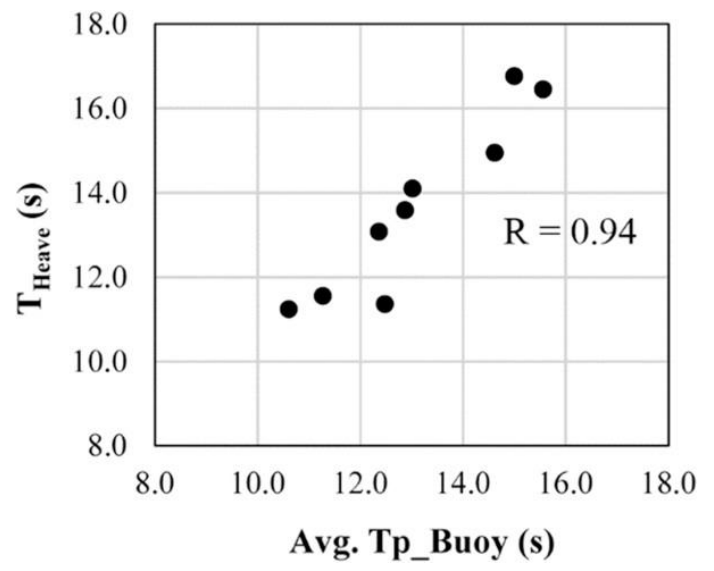

Fig. 20. Scatter plot of peak oscillation periods of heave motion $\left(T_{\text {Heave }}\right)$ vs. the average peak wave period $\left(T_{p_{-} \text {Buoy }}\right)$ outside the port during monitoring time of the gas and small chemical tankers.

Moreover, an approximation of surge natural periods of four representative vessels in the study fleet (3800 DWT gas tanker, 13,000 DWT chemical tanker, 30,000 DWT chemical tanker, and 115,000 DWT oil tanker) has been performed to compare their values with the results obtained in the frequency analysis. The estimation of the natural period of surge (TnSurge) has been made considering the moored vessel as an ordinary mass-spring system:

$T_{\text {nSurge }}=2 \cdot \pi \cdot\left(\frac{M}{K}\right)^{1 / 2}$

where $M(\mathrm{t})$ represents the displacement of the vessel and $K(\mathrm{kN} / \mathrm{m})$ represents the total spring constant of mooring lines in the surge motion direction (only the spring, head, and stern line contribution are considered).

Two different loading conditions (ballasted and loaded) and two expected line stiffness (maximum and minimum) were considered to obtain the TnSurge bandwidth of each vessel type (Table 12).

Table 12. Ship and mooring parameters.

\begin{tabular}{llllll}
\hline \multirow{2}{*}{ DWT } & \multicolumn{2}{l}{ Displacement $(\mathrm{t})$} & & \multicolumn{2}{l}{ Mooring lines } \\
\cline { 2 - 3 } \cline { 5 - 6 } \cline { 5 - 6 } & Ballasted & Loaded & & $M B L(\mathrm{kN})$ & $N$ \\
\hline 3800 & 3908 & 6010 & & 320 & 12 \\
13,000 & 10,588 & 17,472 & & 500 & 10 \\
30,000 & 24,414 & 40,690 & & 500 & 12 \\
115,000 & 63,632 & 134,346 & & 900 & 12 \\
\hline
\end{tabular}


The obtained results are presented in Table 13. By comparing TnSurge values with those obtained in the frequency analysis, it can be observed that only Sichem Singapore (I and II) and Habip Bairak chemical tankers (13,141 DWT and 8400 DWT, respectively) registered surge oscillation periods within their natural frequency band (Table 11, Table 13), and only one of them (Sichem Singapore II) recorded large amplitudes of surge that are close to $2.0 \mathrm{~m}$. These results could explain the absence of large surge motions in most of the analyzed vessels.

Table 13. Estimated bandwidth of surge natural oscillation period of each vessel type.

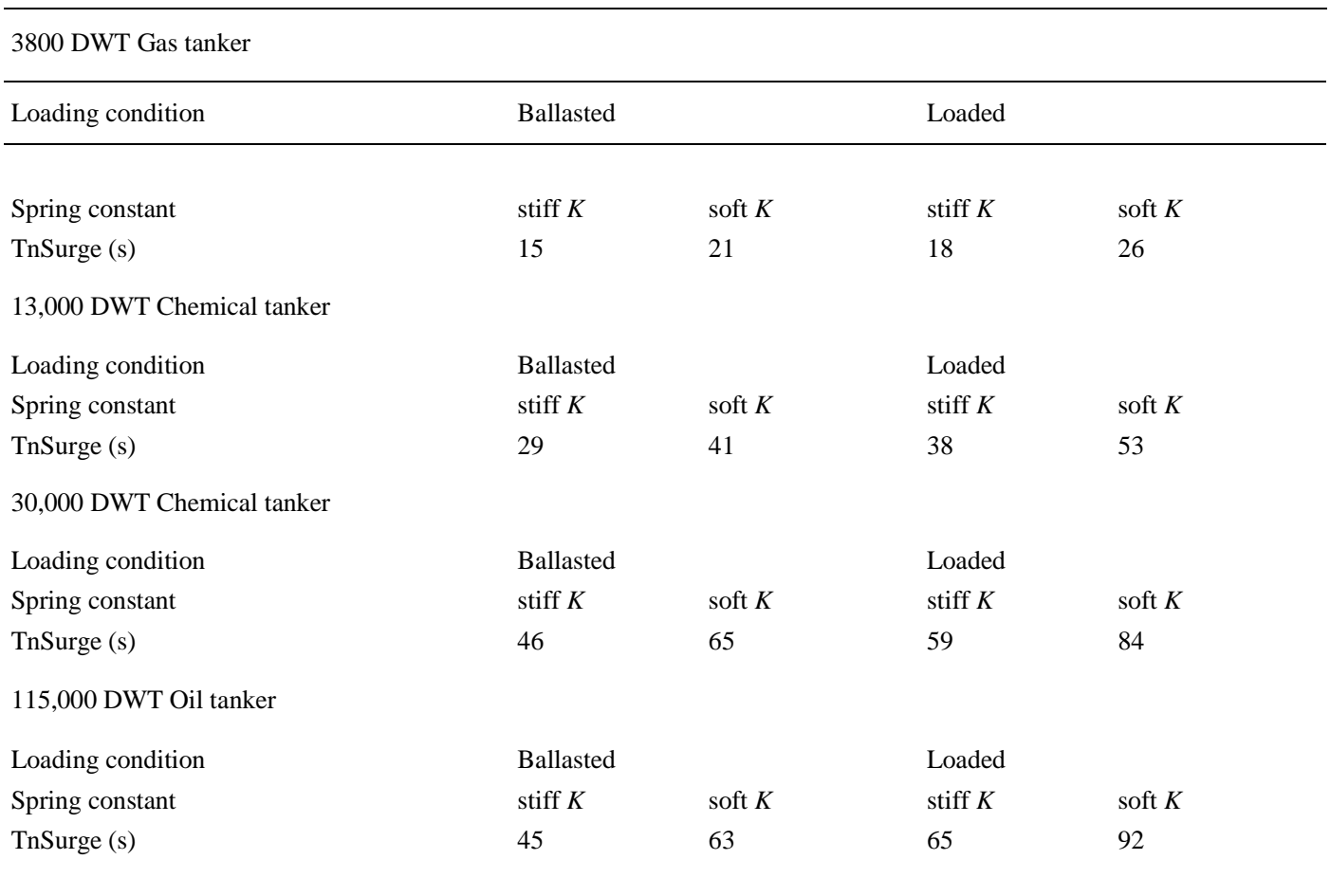

The oscillation periods of a moored ship depend on multiple parameters, such as the berthing location, motion forcings (maritime conditions and wind), loading condition, or mooring configuration. Changes of these parameters can generate variations in those periods even in the same ship. An example can be found in the results of the estimation of surge natural periods. Modifications of the loading condition or the line stiffness generated changes of up to $20 \mathrm{~s}$ in the obtained values, and this variation is greater in large vessels. In addition, these effects can be observed in Sichem Singapore and Scali del Teatro vessels, both monitored twice and three times, respectively, in different loading cycles and berthing locations (1st and 2 nd jetties). These vessels experienced changes in their oscillation periods, being more relevant in the yaw and surge, probably due to the more complex behavior and the significant influence of the mooring system on the horizontal motions. 


\section{Conclusions}

This paper presents the results of a field campaign carried out in the inner port of A Coruña (Spain) for evaluating and comparing the real motions of moored vessels with the safe movement thresholds defined by international standards and to determine if they are applicable to these facilities. The campaign was developed between spring to autumn 2015 and winter 2016 to record the movements of 19 vessels of four different categories (gas tankers, oil tankers, chemical tankers, and general cargo ships) moored at the oil and general cargo terminals of this port during their loading and unloading operations, in adverse wave conditions.

The data analysis revealed large angular motions, especially roll and yaw, including amplitudes exceeding the limiting criteria for safe working conditions of the standards in 13 of the 19 analyzed ships. Despite these large amplitudes, ships could operate normally with no downtime or any consequence affecting safety. These results suggest that thresholds for angular motions represent conservative values for the characteristics of the port analyzed, and therefore, they could be adapted. During the study execution, no downtime was recorded; thus, new thresholds could not be defined.

Regarding linear movements, heave and surge remained at tolerable values in all analyzed ships, which recorded lower amplitudes compared to the standard thresholds. Only two of the analyzed vessels registered surge values that are close to the limits. As with angular motions, the largest movements were found in gas tankers and small chemical tankers of up to $130 \mathrm{~m}$ length moored at the 1st and 2nd jetties of the oil terminal facilities. These results could explain the absence of downtimes despite the large angular motions, suggesting that cargo interruptions would be induced by large linear motions.

Additionally, an integrated analysis of maritime conditions and berthing locations with vessel movements was carried out. Motions showed a good linear relation with significant wave height and peak period outside the port. Differences between the response of small and large vessels were induced by the higher motion restriction introduced by the mooring system of large vessels and the different orientation of their mooring locations. Finally, three linear regression models were constructed to estimate the pitch, heave, and surge responses of vessels moored at the 1 st and 2 nd jetties using wave parameters outside the port ( $\mathrm{Hs}$ and $\mathrm{Tp}$ ) as variables. Adjusted estimators showed reasonable prediction values with RMSEs of $0.056^{\circ}, 0.057 \mathrm{~m}$, and $0.129 \mathrm{~m}$, respectively. These results, although being an initial approximation, show the potential application of regression models as a useful tool to predict risk situations and operational downtimes in ports.

Field campaigns, such as those performed in this work, complemented with wave climate analysis, contribute to evaluate real limiting operation conditions in a specific terminal and their results may lead to establish new limiting criteria according to the characteristics of the port facility. Furthermore, they could be used as an effective tool for assessing the improvement that a specific mooring system could have on port safety and operability.

\section{Acknowledgments}

This research was funded by the Spanish Ministry of Economy, Industry, and Competitiveness, R\&D National Plan, within the project BIA2017-86738-R.

The authors wish to thank the staff of Port Authority of A Coruña and Repsol Maritime Terminal for their cooperation. Moreover, the authors are grateful to the owners and crew of the vessels for their collaboration on board. 


\section{References}

Baker, S., Frank, G., Cornett, A., Williamson, D., Kingery, D., 2016. Physical modelling and design optimizations for a new container terminal at the port of Moin, Costa Rica. In: Oates, D., Burkhart, E., Grob, J. (Eds.), Proceedings Ports '16: Port Engineering, 14th Triennial International Conference - ASCE. American Society of Civil Engineers (ASCE), Varna, Bulgaria, pp. 560-569.

Bont, J. De, Molen, W. Van Der, Lem, J. Van Der, Ligteringen, H., Muhlestein, D., Howie, M., 2010. Calculations of the motions of a ship moored with Moormaster TM units. In: Proceedings of the 32nd PIANC International Navigation Congress. The World Association for Waterborne Transport Infrastructure (PIANC), Liverpool, United Kingdom, pp. 622-635.

Cornett, A., 2014. Physical modelling of moored ships for optimized design of ports and marine. In: Proceedings of the 5th International Conference on the Application of Physical Modelling to Port and Coastal Protection. Varna, Bulgaria.

Davies, M., MacDonald, N., Cornett, A., 2001. Optimization of port design using physical modeling. In: Collins, T.J. (Ed.), Proceedings of the Ports '01: America's Ports: Gateway to the Global Economy, 9th Triennial International Conference - ASCE. American Society of Civil Engineers (ASCE), Norfolk, Virginia, USA.

Figuero, A., Rodriguez, A., Sande, J., Pena, E., Rabuñal, J.R., 2018a. Dynamical study of a moored vessel using computer vision. J. Mar. Sci. Technol. 26, 240-250.

Figuero, A., Rodríguez, A., Sande, J., Pena, E., Rabuñal, J.R., 2018b. Field measurements of angular motions of a vessel at berth: inertial device application. Control Eng. Appl. Informatics. 20, 79 88.

González-Marco, D., Sierra, J.P., Fernández de Ybarra, O., Sánchez-Arcilla, A., 2008. Implications of long waves in harbor management: the Gijon port case study. Ocean Coast Manag. 51, 180201.

Hiraishi, T., Atsumi, Y., Kunita, A., Sekiguchi, S., 1997. Observations of long period wave and ship motion in Tomakomai-port. In: 7th International Offshore and Polar Engineering Conference (ISOPE). Honolulu, USA, pp. 546-551.

Jensen, O.J., Viggosson, G., Thomsen, J., Bjordal, S., Lundgren, J., 1991. Criteria for ship movements in harbours. In: Edge, B.L. (Ed.), Proceedings of the 22nd International Conference on Coastal Engineering (ICCE). American Society of Civil Engineers (ASCE), Delft, The Netherlands, pp. 3074-3087.

Kwak, M., Pyun, C., 2013. Computer simulation of moored ship motion considering harbor resonance in Pohang New Harbor. In: Ostbo, B.I., Oates, D. (Eds.), Proceedings of the Ports '13: Success through Diversification, 13th Triennial International Conference. American Society of Civil Engineers (ASCE), Seatle, Washington, pp. 1415-1424.

López, M., Iglesias, G., 2014. Long wave effects on a vessel at berth. Appl. Ocean Res. 47, 63-72.

Peña, E., Figuero, A., Sande, J., Guerra, A., Perez, J.D., Macineira, E., 2017. Integrated system to evaluate moored ship behavior. In: Proceedings of the ASME $36^{\text {th }}$ International Conference on Ocean, Offshore and Arctic Engineering (OMAE2017). American Society of Mechanical Engineers (ASME), Trondheim, Norway.

PIANC, 1995. Criteria for movements of moored ships in harbours: a practical guide. Rep. Work. Gr. No 24. Perm. Tech. Comm. II, Suppl. to Bull. $\mathrm{N}^{\circ} 88$.

Puertos del Estado, Autoridad Portuaria de A Coruna, 2017. Cuadro de Mando Ambiental- PuertoA Coruna. URL. http://cma.puertocoruna.com/ (accessed 11.28.2017).

Puertos del Estado, 2011. ROM 2.0-11. Recomendaciones para el proyecto y ejecución en Obras de Atraque y Amarre. Ministerio de Fomento, Madrid, Spain.

Robertson, S.P., Weiss, E., Hugo, G.D., 2014. A block matching-based registration algorithm for localization of locally advanced lung tumors. Med. Phys. 41.

Rosa-Santos, P., Taveira-Pinto, F., Veloso-Gomes, F., 2014. Experimental evaluation of the tension mooring effect on the response of moored ships. Coast. Eng. 85, 60-71.

Sakakibara, S., Saito, K., Kubo, M., Shiraishi, S., Nagai, T., Yazaki, F., 2001. A study on long-period moored ship motions in a harbor induced by a resonant large roll motion under long-period waves. In: Proceedings of the 11th International Offshore and Polar Engineering Conference. Stavanger, Norway, pp. 326-333.

Taveira Pinto, F., Veloso Gomes, F., Rosa Santos, P., Guedes Soares, C., Fonseca, N., Santos, J.A., Moreira, A.P., Costa, P., Brogueira Dias, E., 2008. Analysis of the behavior of moored tankers. In: Proceedings of the ASME 27th International Conference on Offshore Mechanics and Arctic Engineering (OMAE2008). American Society of Mechanical Engineers (ASME), Estoril, Portugal, pp. $755-764$. 
van der Molen, W., Scott, D., Taylor, D., Elliott, T., 2015. Improvement of mooring configurations in Geraldton Harbour. J. Mar. Sci. Eng. 4, 3.

Xu, M., Shang, Y., Jin, K., 2015. An effective algorithm for motion estimation of human faces. In: Proceedings of the Visual Communications and Image Processing Conference, VCIP 2015. Institute of Electrical and Electronics Engineers Inc.(IEEE), Singapore. 